\title{
Sociedad y administración del territorio en el tagr al-'alà: El ejemplo del iqlím de Qutanda
}

\author{
Julián M. Ortega Ortega*
}

Para Antonio y Clemente, sin duda

Sin que sea necesario partir de una pormenorizada revisión historiográfica, no parece que haya excesivos problemas en admitir que la organización de la sociedad islámica asentada en la tierras de la Marca Superior es seguramente uno de los temas menos abordados de la ya de por sí poco frecuentada historia de al-Andalus en el valle del Ebro. Una mínima prospección bibliográfica puede poner este hecho de manifiesto (p.e. VIGUERA, 1988: pp. 249286). Frente a tal posición, las notas que siguen a continuación parten del convencimiento de que la cuestión de la desaparición de los estados islámicos en el valle del Ebro ha de enfocarse desde el estudio de la dinámica de desintegración de la sociedad andalusí, por lo tanto no sólo como un proceso favorecido por el desarrollo expansivo de la formación social que acabó por sustituirla, la aragonesa, sino sobre todo como consecuencia de un bloqueo interno que impidió el desarrollo de fórmulas efectivas de resistencia ante la imparable potencia militar de los cristianos. Esta postura no sólo se hace en el sentido de restituir a la sociedad andalusí su plena legitimidad como sujeto histórico, sino, a la vez, en el de resituar conceptualmente el proceso de sustitución de formaciones sociales sobre un mismo espacio que la historiografía tradicional denominó "reconquista y repoblación". Un feliz ejemplo de la pertinencia de tal perspectiva lo ofrece el trabajo de C. Laliena y Ph. Sénac (1991) sobre los orígenes de la expansión aragonesa sobre al-Andalus, donde el estudio del avance cristiano corre paralelo al de la estructura social y política de las zonas más septentrionales de la Marca Superior. Desde este punto de vista, el estudio de las estructuras socio-políticas que caracterizan la última fase andalusí en el valle del Ebro constituyen una necesidad ineludible para entender y explicar el proceso de sustitución y desintegración de tales estructuras. Muestra de las posibilidades de esta línea de trabajo son los abundantes y ya clásicos trabajos de los investigadores de la Casa de Velázquez, especialmente los referentes a la organización del territorio, sin duda uno de los enfoques más provechosos de la reciente investigación sobre al-Andalus. No será distinto el enfoque en esta ocasión. El fuerte carácter regional de esta perspectiva de análisis ha desembocado a la larga en un evidente desequilibrio en nuestro conocimiento general sobre la cuestión. Así, mientras en algunas zonas el nivel resulta más que aceptable, como ocurre con el entorno de Huesca, donde los estudios de Ph. Sénac y C. Escó han constituido una de las bases fundamentales para nuestro conocimiento de la sociedad andalusí en la Marca Superior (SÉNAC y ESCÓ, 1991; SÉNAC, 1991, etc.), otras, como el propio valle del Ebro, permanecen todavía con grandes lagunas, a excepción quizás de la zona de Lérida (GIRALT, 199I; ERITJA, 1994; BOLÒS, 1993), situación que se agrava en los márgenes meridionales de la antigua Marca Superior, donde el panorama nos es casi completamente des-

\footnotetext{
* Seminario de Arqueología y Etnología Turolense. Facultad de Humanidades y Ciencias Sociales de Teruel
} 
conocido. Sólo de forma muy reciente se ha emprendido la tarea de solventar estos problemas. Los recientes estudios sobre la red de regadíos implantada desde época andalusí en la zona de Almonacid de la Cuba (Zaragoza), llevados a cabo por varios miembros del Departamento de $\mathrm{H}^{\mathrm{a}}$. Medieval de la Universidad de Zaragoza, son un buen ejemplo de ello (ARENILLAS et alii, 1996; UTRILLA, 1996; SESMA et alii, 1996). La necesidad de continuar ampliando las áreas de estudio y reduciendo la escala de los análisis parece, pues, clara.

\section{LA ORGANIZACIÓN POLÍTICO- ADMINISTRATIVA DE UN TERRITO- RIO: EL IQLIMM DE QUTANDA}

\section{Qutanda, un ḥiṣn?}

Las informaciones escritas más antiguas que poseemos sobre Qutanda se remontan al siglo VIXI. Es al-'Ud̆rī (m. 478/l 086) el primer autor que nos aporta alguna noticia sobre la cuestión (ver apéndice I-I). De forma sucinta, el autor almeriense dice que Qutanda era uno de los aqālimm (sing. iqlimm) dependientes de Zaragoza, sin especificar nada acerca de qué tipo de asentamiento era el propio enclave de Cutanda (GRANJA, F. de la, 1967: p. 459, nº 8; SOUTO, 1992: pp. 128-9). Tampoco las referencias, más tardías, de al-Idrīīi (m. 560/I l 65) permiten extraer conclusión alguna sobre este punto, ya que sólo nos habla de este lugar como una etapa del camino de Zaragoza a Valencia sin precisar más (ver apéndice I-2). Deberemos esperar al siglo VII/XIII para que Yāqūt (m. 626/I228-9), el único autor que se define en este punto, haga referencia a Cutanda empleando la palabra balda (ver apéndice 1-3). Desgraciadamente, este término no aporta excesiva claridad, ya que parece tener un carácter bastante genérico (SOUTO, 1992: p. I19). El mismo Yāqūt por ejemplo alude a la propia capital de la Marca Superior, Zaragoza, como balda (ABD AL-KARIM, 1974: p. 181 ), término que igualmente utiliza para referirse a Tarragona (ABD AL-KARIM, 1974: p. 22I) o a Daroca, a la que también llama medina e incluso alquería en otros pasajes de su Mu'ŷam al-buldān (ABD AL-KARIM, 1974: p. 161; SOUTO, 1991: p. 125). Aunque generalmente Yāqūt utili- za la palabra balda para referirse a asentamientos de cierta consideración (no aparecería en su obra si fuera de otra manera), lo confuso de su empleo no permite ninguna conclusión segura al respecto. En todo caso, el hecho que Qutanda aparezca en al-'Uḍī como centro de un iqlimm permite pensar que este enclave tuviera un papel significativo en la red de poblamiento de la zona, al menos desde mitad del siglo VIXI y posiblemente desde bastante antes, papel que perfectamente pudo desempeñar mediante la presencia de un qā'id al frente de un hiṣn. Sabemos que algunos otros centros rectores de aqālimm de la jurisdicción de Zaragoza controlaban a su vez a otros hușūn. Es el caso del cercano hișn al-Munastirr, es decir Almonacid de la Cuba, que dependía a su vez de Bilšid, seguramente Belchite, centro de uno de estos aqâlìm, vecino del de Cutanda (GRANJA, F. de la, 1967: p. 14; ABD AL-KARIM, 1974: p. 124; SOUTO, 1992: pp. 123-5). Se puede pensar por lo tanto que también el iqlīm que administraba las tierras del entorno del Pancrudo estuviera organizado de forma similar, con un hișn central en la misma Cutanda y quizás algún(os) otro(s) secundario(s).

\section{El iqlīm de Qutanda: algunas consideraciones sobre sus límites}

La otra información que nos ofrece al-'Udِrī en su breve alusión a Qutanda es que el nahr Baltaš, que en otra parte de su obra identifica con el Huerva (Warba), tenía su nacimiento en el territorio del iqlimm de Cutanda, concretamente en un lugar llamado faŷy Badra (GRANJA, F. de la, 1967: p. II, n. 4; SOUTO, 1992: pp. 133-4). Tenemos así un primer dato para intentar delimitar geográficamente el espacio en el que se emplazaba este distrito (Fig. I). Recientemente, J. A. Souto (1992: pp. 124-5) ha propuesto identificar el castillo de Pedro, aludido por al-Rāzī, con el hișn Baytara, mencionado por Yāqūt y, siguiendo a al-Ahwānī, con el citado faŷy Badra. Basan ambos autores esta afirmación en la referencia que el cronista cordobés hace de los desfiladeros que se localizaban en las cercanías de este castillo y que deben corresponder a los localizados en el río Piedra, adyacentes al famoso monasterio del mismo nombre. A pesar de que la hipótesis de J. A. Souto 
es interesante, no hay razón para no seguir fiel-

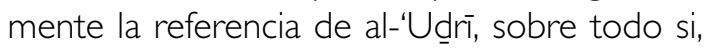
como veremos, ésta revela una gran coherencia. Un simple vistazo a la geografía de la zona donde el Huerva tiene su nacimiento nos hará comprobar la exactitud de la descripción de al'Ud̆rī. Efectivamente, el nacimiento del Huerva se sitúa a menos de diez kms. de Cutanda en línea recta, concretamente en el actual Puerto de Fonfría, a 1.247 mts. de altura, entre la zona del Retuerta al S. (I.492 mts.) y la impresionante alineación constituida por la Muela de Anadón las sierras de Oriche y de Cucalón, al N., donde se alcanzan los $1.478 \mathrm{mts}$. de altura. La orientación NW-SE. a lo largo de más de 15 kms. hace perfectamente aceptable que al-' $U d \underline{d i ̄}$ denominara a esta zona faŷy, "desfiladero". Hay que tener en cuenta además que la primera mención que poseemos de las sierras de Oriche, en la carta de poblamiento de Monforte de Moyuela de II57, aparecen referidas como lapidem fixum que vocatur Petra-fixa (LEDESMA, 1991: p. 105, n 82), dando así nombre a la actual localidad de Piedrahita. Recogiendo los mismos argumentos filológicos que expone $\mathrm{J}$. A. Souto para localizar Badra en el río Piedra, es posible pensar que el fâŷy Badra de al-'Udrī no sea otra cosa que el citado Petra-fixa de I I 57. Por lo tanto, parece bastante probable que las informaciones de al-'Udrī fueran correctas, especialmente si tenemos en cuenta que todo apunta a que este autor pasó por las cercanías de esta zona de camino a Zaragoza (GRANJA, F. de la, 1967: pp. 450, nº 2, y 455-6).

Tenemos por lo tanto bien enmarcado lo que constituía el núcleo del iqlīm de Cutanda: el nacimiento del Huerva y la propia población de Cutanda. Ahora intentaremos aproximarnos a cuáles eran los límites del distrito. Los sectores donde éstos aparecen de forma más nítida son los situados al norte y occidente. Para delimitar el iqlīm por el W. no contamos con ninguna información contemporánea a al-'Uḍrī. Sí se puede traer a colación, en cambio, una conocida noticia del Muqtavis V de Ibn Hayyān, tomada a su vez de al-Rāzī, en la que describe la ruta seguida por el califa an-Nāșir en su campaña del 322/937 contra Zaragoza (ZANóN, 1986). El ejercito encabezado por 'Abd al-Rah. mān an-Nāșir siguió el eje del jiloca de S. a N. por mahallat L.nqa, que debe ser identificada sin grandes dudas con el Poyo del Cid, la antigua Leonica (GÓMEZ-PANTOJA, 1989-90), siguiendo después por Calamocha (hiș̣n Qalamūša), por hișn ar-Rayāḥin del distrito ('amal) de los Banū Razin, por marŷ̀ Taw.b.r, una de las alquerías situadas sobre el río (al-wāḍil), cerca de Daroca (Darūqa), hasta alcanzar mahallat aș-Ṣafșâf, perteneciente ya al distrito ('amal) de Zaragoza hasta alcanzar Muel (mahallat Mulah), sobre el río Huerva (nahr Baltaš). J. Zanón (1986: pp. 479), en su estudio de este trayecto no consigue identificar los tres últimos topónimos citados después de Calamocha, el hișn ar-Rayāhīin, el lugar de marŷ Taw.b.r. y la acampada de aș-Șaf̦ẫf. Además propone seguir este trayecto por la misma ruta que describe al-'Udrī, es decir, por Calamocha, Daroca, Alfamén y Zaragoza (GRANJA, F. de la, 1967: pp. 455-6, n² 2). No obstante, puede plantearse otra interpretación si tenemos en cuenta que en la Edad Media y Época Moderna el camino habitual desde Valencia a Zaragoza no pasaba por Daroca, sino que se dirigía precisamente desde Calamocha hasta el Huerva, siguiendo luego el cauce del río hasta Muel y Zaragoza (GARGALLO y SÁNCHEZ, 1984). Según esta hipótesis, se pueden hacer algunas sugerencias sobre los límites occidentales del iqlimm de Cutanda.

En primer lugar, dentro de la ruta propuesta, los tres misteriosos topónimos deben ser localizados al N. de Calamocha y al S. de Muel, es decir, entre el Barranco de Cuencabuena, que une con el curso alto del Huerva y el curso medio de este mismo río. Suponiendo que cada uno de estos hitos del camino se separara de los restantes por un trecho relativamente homogéneo y equidistante es posible pensar que, de N. a S., mahallat aș-Ṣafșâf se situara hacia Cariñena, dentro del 'amal de Zaragoza y posiblemente dentro del iqlimm de Balțaš, emplazado, según al-'Ud̆rī y al-Himyarī, sobre el curso del Huerva, alrededor de Muel (Muwala) (GRANJA, F. de la, 1967: pp. 459, no 8; SOUTO, 199I, 122; SOUTO, 1992: pp. 138-9). Por su parte, la alquería de Taw.b.r podría localizarse hacia VilladozBadules, a unos diez kms. de Daroca, sobre el propio río Huerva, no sobre el jiloca, como parece sugerir J. Zanón (1986, 48; SOUTO, 1992: pp. 143, n. 284). F. J. García Marco (1993, 38-9, n. 36) 
por su parte opina que debe situarse en Torres - Valtorres. Entre ambos asentamientos habría que localizar el límite entre los distritos califales de Calatayud-Daroca y de Zaragoza. Por último, el hișn ar-Rayāhiin se situaría posiblemente al final del Barranco de Cuencabuena o Barranco Hondo, en torno a la misma población de Cuencabuena o hasta Lagueruela, con la que el límite NE del 'amal califal de los Banū Razīn y seguramente de la posterior taifa de Šantamariyya, se localizaría en torno a esta zona. Si esta deducción es correcta, podría identificarse el hiṣn ar-Rayāhīn con El Castillejo (Lechago), localizado en el Barranco del Regajo, a un $\mathrm{km}$. del Barranco de Cuencabuena, aprovechando un importante cerro testigo (BURILLO MOZOTA, 1979; BURILLO JIMÉNEZ, 199/b). Conserva restos de un torreón de planta cuadrada, de 5'5 mts. en el extremo E. pero los restos de un importante recinto amurallado bordean todo el cerro (Lám. I y 2). El poblado se localizaba en la base, aprovechando una pequeña vaguada. La existencia de la fortificación durante la segunda mitad del siglo VIXI y principios del siglo VI/XII está fuera de toda duda. Los materiales aparecidos lo confirman. El tipo de ollas habituales en la zona, frecuentemente cubiertas al interior por una fina capa de vidriado y decoradas al exterior con goterones de manganeso combinados con incisiones a peine formando bandas horizontales pertenecen a este momento. Lo mismo puede decirse de la también frecuente aparición de restos de grandes vasijas de almacenamiento con el carácterístico borde en perfil de "palo de golf" y decoradas con motivos plásticos, bandas unguladas horizontales sobre todo, que se combinan con lineas incisas a peine onduliformes y horizontales de aspecto poco cuidado. Este tipo de grandes contenedores de almacenamiento es habitual también en la comarca de Cuencas Mineras, aunque la extensión de este tipo es mucho más amplia, abarcando prácticamente todo el valle medio del Ebro, como parecen indicar su aparición en las comarcas de Calatayud, en Daroca, por ejemplo en Cerro Almada (Villareal de Huerva) (C.A.A. 89-90, 1993a) o en El Castillejo (Mainar) (C.A.A. 89-90, 1993c), e incluso en la zona de Las Bardenas Reales, en Navarra (SESMA Y GARCÍA, 1994: pp. 204, f. 25).
El iqlīm de Cutanda, por lo tanto, limitaría con los Banū Razinn en la propia depresión del Jiloca a occidente y el citado Barranco de Cuencabuena, por el sector NW. Esta suposición está avalada además por una referencia de la Historia Roderici en la que queda claro que los límites septentrionales de la taifa de los Banū Razīn en tiempos de Hussam al-Dawla permanecían invariados desde el califato, es decir, entre Calamocha y Daroca (MENÉNDEZ PELAYO, 1943, I: pp. 357-9, y ll: p. 934; BOSCH VILÀ, 1959: p. 60; ALMAGRO BASCH, 1956). Al N. el iqlimm de Cutanda limitaría con el distrito de Calatayud/Daroca, que cortaría por el mismo cauce del Huerva. Por lo que respecta a la zona NE., ya hemos visto que el nacimiento del Huerva se incluía en el distrito de Cutanda, aunque no es posible precisar más. Por coherencia geográfica puede pensarse que el límite con el vecino iqlīm de Bilšĩ se establecía por la misma sierra de Oriche, de este modo el distrito de Belchite-Almonacid de la Cuba ocuparía toda la cuenca hidrográfica del Aguasvivas (SOUTO, 1992: pp. 123-4; UTRILLA, 1996; ARENILLAS et alii, 1996; SESMA et alii, 1996), aunque no puede descartarse que, al menos las estribaciones septentrionales de la Sierra de Oriche fueran controladas por Cutanda. Tampoco podemos precisar gran cosa acerca de los límites medirionales y orientales. Puede suponerse, por los mismos argumentos de coherencia geográfica, que todo el valle del Pancrudo constituía el eje del iqlimm, quedando separado de todo el importante valle del Martín, a oriente, y del valle Alfambra, al SE., del que sabemos por Yāqūt que formaba una nāhiya con identidad propia dependiente de Zaragoza (ABD AL-KARIM, 1974: pp. 62-3; SOUTO, 1992: pp. 122-3).

\section{Cutanda, Daroca, Zaragoza}

No parece que haya demasiadas dudas en la dependecia directa de Cutanda respecto de Zaragoza en todo momento (sobre el 'amal de Zaragoza ver SOUTO, 1991). A pesar de la extrañeza de E. Manzano sobre el hecho de que al'Udrī atribuya el iqlimm de Cutanda directamente a Zaragoza en lugar de integrarlo en el distrito, más próximo, de Calatayud y Daroca, según el esquema de administración del territorio califal descrito por al-Rāzī (MANZANO, 
1991: pp. 126-7), lo cierto es que el único argumento que permite pensar en esta dependecia parte de una noticia de al-Maqqarī, quien, a pesar de que su texto no es esencialmente geográfico, nos transmite un interesante dato al describir la batalla de I I 20 (ver apéndice I4). Según este autor, Cutanda se localizaba "... en la zona de Daroca, distrito de Zaragoza, en la Frontera Superior" (GAYANGOS, I843, II: p. 304; UBIETO, 198I: p. 176). Ciertamente, lo lacónico de la referencia no permite extraer, de nuevo, conclusiones demasiado seguras. Al-Maqqarīparece utilizar a Daroca más bien como simple punto de referencia geográfica. En todo caso, lo primero que hay que advertir, y en esto radica quizás su interés, es que la noticia no sugiere ningún tipo de dependencia de Cutanda respecto de Calatayud, sino, en todo caso, de Daroca. Al-Maqqarī no alude pues a la organización del territorio descrita por al-Rāzī, sino a la del final de las taifas. Lo mismo ocurre con la comentada noticia de al-'Ud̆rī, referida quizás a la organización administrativa existente tras la reunificación de la taifa llevada a cabo por al-Muqtādir, después de que, a la muerte de Sulaymān b. Hūd, ésta se dividiera entre sus hijos, pasando Daroca a formar parte una de estas dependencias, la de Calatayud, en manos de Muhammad b. Sulaymān b. Hūd 'Adad al-Dawla (TURK, 1978: pp. 69ss.). De todas formas, no sería extraño que, como ocurrirá con otras ciudades a finales del siglo V/XI, Molina o Medinaceli por ejemplo, Daroca hubiera sido capaz de desarrollar una cierta autonomía, al abrigo del desarrollo urbano que parece caracterizarle durante la segunda mitad del siglo VIXI (ORTEGA, 1996). En este contexto es posible que Cutanda pudiera haber estado en la órbita de Daroca. De todas formas, lo sucinto de la noticia no permite ir más allá. Hay que recordar, por otra parte, que todavía a mediados del siglo V/XI Ibn Hazm integra a Qurbala (Corbalán, Teruel) en las dependencias de Zaragoza (MANZANO, 1991: pp. 149-150 y 212-3) y Yāqūt, dos siglos después, hace lo mismo con el Alfambra (ABD AL-KARIM, 1974: pp. 62-3; SOUTO, 1992: pp. 122-3), lo que indica claramente que estos territorios, mucho más meridionales que la propia Cutanda, también dependieron en algún momento directamente de Zaragoza.

\section{El iqlīm de Qutanda y la administración del territorio en época de taifas}

No cabe duda que el iqlīm, como unidad de administración territorial, tuvo una importancia central durante las taifas. Las propias referencias de al-'Udֵrī son buena prueba de ello, pero no la única. A finales del periodo taifa, la administración judicial de Córdoba seguía empleando el iqlím y la jurisdicción de la ciudad como fórmula para la localización cualquier población o alquería. Así por ejemplo un veredicto (fatwà) recogido en los Nawazil de Ibn al-Haŷy, fechado en 475// 085-6, localizaba a Munt Inyāna en el iqlīm de Rub' Ash-Sha'rā', del 'amal (jurisdicción) de la ciudad de az-Zahrā', o a Uktābat al-Maqāfi, del iqlīm de Al-Mubansițār, del 'amal de Córdoba (BENABOUD y BENSBAA, 1993: p. 261).

A pesar de todo, desconocemos en gran medida cuál es la naturaleza de la unidad de administración del territorio que las fuentes árabes denominan iqlimm. Varias son las opiniones que se han vertido al respecto. Algunos autores ven en el término una simple referencia geográfica. J. Vallvé (1986: p. 236) por ejemplo le da el sentido de "comarca natural". No obstante la mayoría de las hipótesis parecen estar de acuerdo en el carácter claramente administrativo del término, siguiendo a $\mathrm{H}$. Monés (1956) que interpretó en su dia el iqlím como una fórmula administrativa dirigida a ordenar espacios de economía basicamente agrícola, frente al $\hat{y} u z^{\prime}$ fundamentalmente ganadero $y$ caracterizado también por un régimen fiscal peculiar. Parecido sentido, "división agrícola de base financiera", es el que da G. Abd al-Karim (1972: p. 28), quien, a partir de las informaciones proporcionadas por Yāqūt, identifica iqlīm con rusțāa y nāhiya. Por su parte, L. Cara y J. $M^{a}$. Rodríguez (1992: p. 72, n. 42) han vuelto a insistir en el carácter eminentemente fiscal de los aqālìm siguiendo el testimonio tardío de Ibn Sa'id, cuando alude a ellos en alguna ocasión como 'amal. M. Barceló (1984: pp. 9I-2), a partir de las datos ofrecidos por al-'Udrī y Yāqūt, opina que, en el caso mallorquín, los aqālim debieron ser unidades administrativas reducidas, pero densamente pobladas, seguramente equivalentes al rusțāq oriental y de emi- 
nente carácter fiscal. A partir de las noticias de al-'Udrī sobre los aqālimm dependientes de Zaragoza, J. A. Souto (1992: p. 115) concreta algo más esta opinión y piensa que el término iqlìm debe ser interpretado como un distrito agrícola especializado en una economía de regadío, ya que la mayoría de los aqālimm citados por el autor almeriense en el valle del Ebro giran en torno a importantes arterias fluviales.

Efectivamente, tres parecen ser los elementos fundamentales que definen al iqlim: su naturaleza administrativa, su carácter fiscal y su coherencia geográfica en torno a ejes fluviales. Quizás el primer punto sea el más claro. No hay duda de que los aqälìm eran las unidades de administración territorial en las que quedaba dividida la kūra califal o el 'amal de época taifal en las tierras que quedaban fuera del hawz al-madina. Algunas de estas coras y amales se organizaban sólo mediante aqālimm como ocurre en Córdoba, dividida en 15 aqālìm. Lo mismo ocurría en las coras de Tudmirr, Sidonia, Niebla, Zaragoza, Sevilla (VALLAVÉ, 1986: p. 235; SOUTO, 1992: p. 117 ; ROLDÁN, 1993: pp. 11 10-125) O Huesca, según información del Dikr bilād alAndalus (SOUTO, 1992: p. 117). Otras coras se organizan a través de la combinación de aqālimm y aŷza' (sing. $\hat{y} u z)$. Así ocurre con Algeciras, en Ilbirra, donde al-'Ud dīi menciona 25 aqālimm y 26 ấza' (SÁNCHEZ MARTíNEZ, 1975-76), o en Valencia, donde el mismo autor alude a 14 aýza', generalmente al sur del Palancia, y 10 aqālìm, al norte (VALLVÉ, 1986: p. 293). Otras coras únicamente presentan aŷza', como parece ocurrir en Mallorca a partir de los datos al-'Ud Yāqūt y del Repartiment (BARCELÓ, 1984).

Respecto al segundo punto, la naturaleza fiscal del iqlimm tampoco resulta excesivamente problemática, ya hemos visto varias opiniones al respecto. Las informaciones transmitidas por al-'Udِrī y el Dikr bilād al-Andalus a propósito de la recaudación fiscal de las coras de llibira y Córdoba, donde el iqlimm aparece claramente como una unidad básica de organización de la fiscalidad rural, son testimonio suficiente (VALLVÉ, 1986: pp. 254-6 y 27I-3).

Por último, tampoco parece haber duda de que el iqlìm se carácteriza por su coherencia geográfica. Seguramente de ello derivan las relaciones entre el iqlimm y la nāhiya. Las referencias a nawāḥi (sing. nāhiya) en al-Andalus son en general tardías, principalmente de Yāqūt, aunque anteriormente ya $\mathrm{lbn}$ al-Farad̦i (m. 403/l0 /3) o al-'Uḍri emplean la expresión (VALLVÉ, 1986: p. 233), al igual que Ibn Gālib (siglo $\mathrm{VI} / \mathrm{XII}$ ), posteriormente recogido por el propio Yāqūt, cuando alude por ejemplo a la nāhiya de Zanāta, dependiente de Zaragoza (ABD ALKARIM, 1974: p. 173). En principio, su significado parece hacer referencia a toda zona geográfica que comprenda un número de ciudades y alquerías, aunque Yāqūt informa de forma expresa que en algunos contextos, como ocurre cuando habla de Ulya, uno de los aqālìm de la cora de Sevilla, "La palabra iqlimm corresponde aquí a una alquería grande en su conjunto" (ANAD AI-KARIM, 1974: p. 89; ABD AL-KARIM, 1972). Quizás por ello Leví-Provençal (1957: p. 26) se inclinaba a pensar que la nāhiya no había tenido nunca un valor oficial en al-Andalus, opinión compartida por J. A. Souto (1991: p. 122; SOUTO, 1992: p. 1 15). Además, no cabe duda que debió existir algún tipo relación entre la nāhiya y el iqlīm. Así, Yãqūt, al describir la cora de Rayya, comenta que los magrebíes utilizaban el termino nāhiya con valor análogo al de iqlìm (ABD ALKARIM, 1974: p. 17I) y el mismo autor, al hablar de Calatrava, dice "Comprende cierto número de alquerías y de nawāhini, a los que se les llama también ayza', término que aplican con el mismo valor que iqlīm..." (ABD AL-KARIM, 1974: p. 165). Esto es coherente con la referencia que al-'Udrī hace a la nāhiya de Balad Nuwabo, que sitúa en el iqlīm Funtus, de la jurisdicción de Zaragoza (GRANJA, F. de la, 1967: p. 459), donde queda claro que la nāhiya es un sector del iqlīm. Respecto al carácter "fluvial" del iqlīm, del que posiblemente derive su identificación con la nāhiya, resulta especialmente patente en el propio 'amal de Zaragoza, donde todos los aqāIim se localizan sobre importantes arterias fluviales, al igual que ocurre en Huesca, donde el Dikr bilād al-Andalus también menciona la existencia de cinco aqālimm en torno a cuencas fluviales (SOUTO, 1991: p. 122; SOUTO, 1992: p. 117). Lo mismo puede decirse en lo referente a la economía de regadío que parece caracterizar al iqlimm. El reciente estudio de Arenillas y otros (1996; SESMA, et alii, 1996; UTRILLA, 1996) sobre la 
infraestructura hidráulica en la cuenca del Aguasvivas demuestra fehacientemente la importancia de la agricultura intensiva de regadío en el iqlimm de Belchite y Almonacid, vecino, como ya hemos dicho, del de Qutanda.

Resumiendo todas estas interpretaciones, puede pensarse que el iqlimm era una unidad de administración territorial, de carácter eminentemente fiscal, formada por el conjunto de alquerías que tributan a una medina $\mathrm{o}$ a un hișn, que se establecía sobre los límites de un espacio geográficamente coherente, a menudo una cuenca fluvial, lo que determinaba su vocación económica hacia una agricultura intensiva de regadío.

\section{EL IQLIMM Y LA ESTRUCTURA DEL POBLAMIENTO}

\section{Hiiṣn-Qarya-Burŷ: la estructura básica del pobla- miento del iqlīm en las fuentes escritas}

No parece haber demasiadas dudas de que la estructura básica del poblamiento en al-Andalus se organizó desde época omeya mediante la articulación de tres tipos de centro de poblamiento: castillos o hușūn (sing. hișn), alquerías o qura (sing. qarya) y torres o burūŷy (sing. burŷ). Así parece sugerirlo el Dikr bilād al-Andalus, cuyas fuentes parecen proceder directamente de los registros fiscales califales. Al hablar de la cora de Cabra por ejemplo menciona la existencia en ella de 630 alquerías, 300 torres y 70 castillos (MOLINA, 1983, l: p. 25 y II: p. 5I). Parecida estructura de poblamiento es aludida por la misma fuente al describir el trecho que separa Sevilla de Niebla (ROLDÁN, 1993: pp. 105 y 331). Varios de sus pasajes dejan claro además que esta es la estructura del poblamiento propia del iqlīm (VALLVÉ, 1986: p. 236), por ejemplo cuando describe la cora Córdoba, donde también al-'Udِrī alude a la misma organización básica del territorio, como también ocurre en las referencias a Huesca o Zaragoza. De hecho, el Dikr biläd al-Andalus es claro al señalar que todos los aqālimm de Zaragoza contaban con burūŷy en número incontable (fi kull iqlīm minhā; SOUTO, 1992: p. I 17; VALLVÉ, 1986: p. 236).

\section{El registro arqueológico de un iqlīm}

No es cuestión de entrar aquí en los problemas, especialmente presentes para los investigadores del mundo medieval, de las relaciones entre la información escrita y el registro arqueológico (p.e. BARCELÓ et alii, 1988: 21 -52; MALPICA, 1996). En cualquier caso, no puede obviarse un hecho que seguramente constituye la primera y mayor dificultad para el acercamiento y la comprensión de la organización del poblamiento en el iqlimm de Cutanda: frente al esquema hișn-qarya-burŷ de los registros fiscales y administrativos del estado califal y taifa que acabamos de comentar, la documentación arqueológica revela generalmente una variedad morfológica de asentamientos que supera con mucho el esquematismo de la información escrita. Bien ejemplificada en las tipologías de asentamientos ya establecidas para algunas zonas como la levantina (BAZZANA, 1982) o la andaluza (CRESSIER, I99 I: p. 406), parecida variabilidad encontramos en el espacio rural del iqlimm de Qutanda (Fig. 2).

En primer lugar, encontramos los huușūn. No contamos con ninguna referencia escrita directa a la existencia de hușūn en el iqlïm de Qutanda. Hemos visto, sin embargo, que todo parece indicar la presencia de uno de estos hișn en la propia Cutanda en tanto que centro rector del distrito fiscal. Poco es, desde luego, lo que queda de su fortificación andalusí. La propia batalla de II20 dejó con toda seguridad su destructiva huella sobre esta fase de la fortificación, al igual que las obras de rehabilitación que debieron emprenderse inmediatamente después, durante la tenencias de Ato Orella en I I28, Eneco Fortunio en II35, Cajal en II38 y más tarde con Lope Sanz, señor de Belchite, hasta que, antes de II58, pasara a manos de el obispo de Zaragoza. De hecho, obras en el castillo se documentan en 1243, I 500 y I 554. De todas formas, la ruina total le llegó con la demolición que la fortaleza sufrió al final de la última guerra carlista, definitiva para el proceso de desfiguración de la primitiva fábrica musulmana (ANDRÉS, 1960; GUITART, 1987: pp. 47-8; GUITART, 1988: 78-9). Ningún otro dato permite por el momento identificar otros hușūn en este 
iqlīm. A pesar de todo, no sería de extrañar su existencia. Las referencias del Dikr bilād al-Andalus a los aqālimm de Córdoba por ejemplo señalan un mínimo de tres hușūn por iqlìm, aunque estos podían sobrepasar la veintena en los distritos de mayor extensión (VALLVÉ, 1986: pp. 2546).

De especial interés resulta lo referente a los materiales arqueológicos aparecidos. Las prospecciones realizadas por la Carta Arqueológica de Aragón y las posteriores revisiones que precedieron a este trabajo han permitido localizar en el mismo castillo de Cutanda un nivel de destrucción que no puede ser relacionado más que con el suceso del 17 de junio de II 20. Efectivamente, en la ladera NW. del cerro, justo en la base de los escasos restos conservados de la obra gótica y renacentista del castillo, subsiste todavía un corte de más de un metro y medio de altura en el que se acumulan gran cantidad de carbones, tejas, cenizas, vigas carbonizadas y restos derruidos de algún muro, que deben ser relacionados con este momento (Lám. 3 y 4). El hecho de que el lienzo de sillería gótica que forraba este corte sirviera de cantera y fuera desmontado en los años cincuenta para la construcción de una fuente próxima al pueblo ha permitido sacar a la luz este corte y el nivel de destrucción que contiene. La mayor parte del lote de materiales localizado procede precisamente de este punto, lo que permite fechar con bastante seguridad los materiales allí recuperados. Por otra parte, todos los tipos cerámicos de este lote son coherentes con las dataciones relativas que hasta el momento se han venido dando para este tipo de materiales, lo cual reafirma la vinculación de este potente nivel de destrucción con la batalla de Cutanda. Desde este punto de vista, la importancia de contar con una fecha absoluta para datar el registro cerámico localizado en Cutanda afecta de manera muy especial a la posibilidad de precisar a su vez la cronología de materiales similares hallados en el resto de asentamientos andalusíes de la zona, aun dentro del contexto de las cronologías relativas. De este modo se asegura el probable carácter contemporáneo de todos los asentamientos que posean registros arqueológicos con paralelos en Cutanda y que, por ello, debe- rán ser atribuidos con bastante seguridad a las primeras décadas del siglo VI/XII.

Estos materiales son variados. La cerámica común de cocina, como suele ocurrir, se caracteriza por la aparición masiva de ollas y ollitas, por lo general de base ligeramente convexa $y$ cuerpo globular, con pastas de color ocre y tacto cremoso, bien decantadas y con desgrasantes muy finos. Las paredes son también finas, con acanaladuras bien marcadas en el exterior de la panza. A este grupo se unen las ollas de cuello poco desarrollado que revelan unas características técnicas algo distintas. La coloración de sus pastas suele ser más clara, dentro de los ocres pálidos y amarillentos. El desgrasante es más abundante, casi siempre cuarcítico y sus paredes aparecen ocasionalmente raspadas para eliminar el exceso de pasta, especialmente en la base de las piezas. El desarrollo del cuello de estas piezas responde a dos tipos. Pueden aparecer, en primer lugar, ollas sin cuello marcado, uniéndose directamente el cuerpo y el borde como en las ollas tardorromanas. Un grupo carácterístico dentro de este tipo es la olla de cuello acampanado. La decoración puede estar realizada con pintura, en forma de goterones de manganeso, todo ello muy en consonancia con lo que conocemos, por una lado toda la cerámica andalusí del norte de la provincia de Teruel, especialmente con la de la comarca de Cuencas Mineras, el Bajo Aragón, la zona de Daroca y Calatayud. También es frecuente en la decoración de las ollas el uso de líneas horizontales en manganeso que enmarcan otra línea serpenteante, formando un motivo también muy abundante en las producciones comunes de toda la Marca Superior.

Otro tipo de producción muy característico es la cerámica con engobe rojo, de la que han sido detectados dos fragmentos semejantes a las sigillatas romanas, bordes concretamente. Corresponden a piezas de pequeño tamaño de paredes muy finas que deben ser puestas en relación con algunos ejemplares de orcitas localizados en el subsuelo de Zaragoza, procedentes probablemente de los alfares de San Pablo, activos todavía a principios del siglo $\mathrm{VI} / \mathrm{XII}$. Aparecieron también varios fragmentos de formas abiertas cubiertas con vidriados monócromos de distintos tonos, de los 
que destacan los verdes. También son abundantes los monócromos melados, de los que contamos con varios fragmentos informes y un fondo de ataifor. Esta producción en concreto es altamente característica de los valles del jiloca y del Jalón. Su pasta rosada y el tono uniforme de su melado, generalmente claro, la hace perfectamente distinguible. Este tipo de formas son abundantes en todo el valle del Ebro y sus afluentes, especialmente el Jalón y el jiloca, llegando hasta la Marca Media, en la zona de las parameras de Molina, e incluso hasta el sector de Toledo-Madrid.

Como no podía ser de otro modo en materiales que no proceden de una excavación, la aparición de cerámicas vidriadas "finas", como la cuerda seca por ejemplo, es completamente excepcional. En el Castillo de Cutanda se recuperó el único resto de cuerda seca total, el único que ha sido posible localizar en nuestro área de estudio. Se trata de un pequeño fragmento perteneciente a una forma abierta cubierto al exterior con vidriado melado amarillento y al interior con cuerda seca total que combina el verde, el blanco y el melado con el negro de la línea en manganeso.

Otro grupo de asentamientos, mejor representado, son los de vocación claramente agrícola. Asentamientos en llano junto a la vega del Pancrudo, que no hay problemas en identificar como poblados campesinos, alquerías, encontramos por ejemplo en Los Villares (Cutanda). Su carácter agrícola es claro. Prueba de ello es, además de la ausencia de todo tipo de estructuras defensivas, su ubicación en llano junto al curso del río, aprovechando las posibilidades del cultivo irrigado (BURILLO JIMÉNEZ, 199la). Este asentamiento está asociado a una atalaya topográficamente bien diferenciada, el Castillico Cervera (Cutanda), un torreón de sillarejo y mampostería de yeso y cantos (BURILLO y ZAPATER, 1991: p. 243) (Lám. 5).

No obstante, la mayoría de los establecimientos con vocación claramente agrícola corresponde a pequeños asentamientos de nueva planta situados en topografías destacadas, que pueden recordar a la de los castros protohistóricos, pero aquí la asociación con las defensas, fortificaciones y torres es directa; éstas se emplazan yuxtapuestas, contiguas, a las zonas de residencia. Buenos ejemplos los tenemos en el Cerro de la Cesta/Cabecico Redondo (Torre los Negros), un asentamiento situado en la confluencia entre el río Cosa y el Pancrudo, que ocupa un cerro aislado, rodeado por los restos de una muralla, excepto en el sector NW., donde es sustituida por el escarpe natural (Lám. 6). Dicha muralla, de un grosor medio de I'30 mts., utiliza un aparejo bastante irregular que combina el sillarejo de piedra caliza con algunos bloques de mayor tamaño mejor escuadrados, trabado todo con argamasa de cal y cantos (RAMÓN, 1991). Aunque las estructuras del poblado aparecen muy arrasadas, lo que dificulta bastante su identificación, no cabe duda sobre la presencia de una comunidad campesina asociada a esta fortificación, como pone de manifiesto al presencia de algunos silos encontrados en su entorno más inmediato. Por lo que respecta a los materiales, destaca la aparición de un pequeño fragmento de posible falsa cuerda seca, con una mancha de vidriado melado sobre fondo blanco sin restos de la línea de enmarque en manganeso. De todos modos, el reducido tamaño de esta pieza no permite conclusiones demasiado precisas. También son frecuentes las ollas con decoración de líneas horizontales en manganeso que enmarcan otra línea serpenteante. Los paralelos son abundantes en la Marca Superior, especialmente en su sector oriental y siempre con una cronología que varía entre la segunda mitad del XI y la primera del XII. Baste citar, por ejemplo, su aparición en la Plaza de l'Olivera (Tortosa) (CURTO et alii, 1985: p. 108), en la iglesia de Sant Martí (Lérida) (GALLART et alii, 1985, 330, Im. 5.25), en la Plaza de Sant Joan (Lérida), sobre cántaros, en Plà de Almatá (Balaguer, Lérida), sobre fuentes, en el Tossal de Solibernat (Torres del Segre, Lérida), sobre cántaros y tinajas (ESCÓ, 1988: pp. 74, 75, 83, 84, 103 y 130 respectivamente). También en la zona de Huesca podemos observar motivos similares, caso de Bolea (Huesca) (ESCÓ y SÉNAC, 1988: p. 16 y fs. 5.d y 5.e).

Otro posible torreón se localizaría en el asentamiento de El Alto de la Torre la Quin (Bañón), sobre un cerro testigo de las estribaciones de Sierra Palomera, posiblemente en el 
sector fronterizo entre el iqlīm de Cutanda y el 'amal de los Banū Razīn (Lám. 7 y 8). Este yacimiento conserva restos bastante erosionados de un conjunto defensivo formado por dos líneas de murallas que bordean sendos afloramientos escalonados de la cantera y un posible torreón muy arrasado en la cima (HIDALGO, 199lb). Entre los materiales más característicos destacan ollas de cuello recto con acabados habituales en esta zona y decoradas con goterones de manganeso que forman tanto en bandas horizontales continuas como con pequeñas marcas alternantes.

Junto a la misma Rambla del Pinar, tributaria del Pancrudo, se encuentra, aguas arriba, otro asentamiento fortificado: Arrieros (Torrecilla del Rebollar) (Lám. 9). Aunque las labores agrícolas han desmantelado en gran parte el yacimiento y no se conservan prácticamente restos constructivos, la presencia de un importante foso de hasta $4 \mathrm{mts}$. de altura, excavado en el sector SE. del yacimiento, indica claramente el carácter estratégico de este emplazamiento (HIDALGO, 1991a). Los materiales más frecuentes son las ollas características de la zona, ya descritas, sobre todo las ollas de cuello acampanado, aunque también aparecen ollas de cuello recto. Es reseñable igualmente la aparición de algún fragmento de olla con carena marcada en el hombro, del tipo toledano, pero con decoraciones en manganeso típicas de las Marca Superior. También encontramos un lote de cerámica vidriada que, aunque reducido, resulta bastante interesante. Destaca un ataifor con cubierta monócroma de tonos verdes claros y un fondo de redoma de pasta gris achocolatada se cubre con vidriado verde monócromo de tonalidades intensas, similares a las del fragmento de ataifor estampillado que igualmente fue localizado en este yacimiento. Este ataifor debe ser relacionado con los ataifores estampillados del tipo aparecido en el alfar de la C/ Teulada de Denia (GISBERT, 1985: p. 174 y Im. VII), en los testares toledanos (AGUADO, 1983, Im. X) o en varios yacimientos urbanos de Zaragoza (VILADÉS, 1987: p. 224 y Im. I), siempre en contextos de finales del siglo V/XI y principios de la siguiente centuria. En la provincia de Teruel han sido localizados algunos fragmentos más en el área del Bajo Aragón, en Alcañiz el Viejo (Alcañiz)
(BENAVENTE y LASA, 1995: p. 243 y fg. 8.3). Su cronología varía entre la segunda mitad del V/XI y todo el siglo $\mathrm{VI} / \mathrm{XII}$.

Algunas de estas pequeñas fortificaciones se encontraban en el mismo valle del Pancrudo, formando parte del complejo defensivo de la misma Cutanda. La Pedrera (Barrachina) es un buen ejemplo (Lám. 10). Localizado sobre un relieve destacado próximo al Pancrudo, el estado de deterioro que presentan los restos de estructuras constructivas emplazadas en este asentamiento no permite su correcta interpretación, pero todo parece indicar que el amontonamiento de piedras que corona el cerro corresponde efectivamente a un torreón (SOPENA, 1991). La presencia de cerámica de cocina y ollas decoradas con líneas horizontales en manganeso que enmarcan otra línea serpenteante es habitual como en el resto de asentamientos comentados.

Es bastante posible que debamos identificar a estos pequeños asentamientos campesinos asociados a una torre con los burūŷy de las fuentes escritas. En primer lugar, no hay duda que estos burūŷ eran unidades de tributación fiscal, es decir unidades de producción campesinas, al igual que las propias alquerías. Tampoco parece haber duda de que su nota distintiva era la presencia de algún tipo de fortificación menor de tipo torre. Ambas condiciones se cumplen en los asentamientos descritos.

Un hecho a destacar está referido a la estructura de la defensa campesina en esta zona. Como acabamos de ver, ésta se realiza no mediante albacares o recintos colectivos de tipo levantino, sino mediante torres independientes emplazadas en los propios asentamientos. De ellas contamos incluso con alguna noticia en las fuentes literarias, no por lacónica menos interesante. Efectivamente, al aludir a la famosa batalla de I 120, la Crónica de Saint Maixent comenta que los ejercitos cristianos, además de derrotar a los almorávides, también "... plurima alia subiugaverunt castella..." (cit. UBIETO, 1981: p. 161, n. 54). Este hecho permitiría a los aragoneses el control casi inmediato del alto Jiloca y posiblemente de todo el Huerva. Así, en I I 24, por ejemplo, vemos a Alfonso I hacien- 
do importantes y estratégicas donaciones en estos ejes fluviales, por ejemplo la donación a los hermanos Fruela y Pelayo de "... in illo rigo de illa Orba uno castello cui dicitur Luco et Kacim et lorba, ut sint vobis ad vestras propias hereditates, et insuper dono vobis altero castello quem dicitur Alkanic, quod habeatis de illum illas duas partes per vestra hereditate et illa tercia parte quod teneatis illam per honorem pro me..." (UBIETO, 1953: p. 75, doc. 1). El castillo de Alkanic, citado incluso en el verso 936 del Poema de Mio Cid, debe ser identificado con el despoblado de Alcañicejo, en la Ermita de San Bartolomé (Tosos, Zaragoza) (CORRAL y MARTíNEZ, 1987: p. 45; CORRAL, 1991: pp. 38-9). El carácter ciertamente menor de estas fortificaciones queda también claro en otros casos. Tres años después, en 1127, se designa a Quadrat como tenente de Maria, la actual población de María de Huerva, y Almohada, ahora conocido como Cerro Almada (Villareal de Huerva, Zaragoza), un pequeño castro celtibérico amurallado, reocupado en época andalusí (UBIETO, 1973: p. 267; BURILLO MOZOTA, 1980: pp. 85-7; C.A.A. 89-90, 1993a: pp. 30I-2). Parece, por tanto, claro que, gran parte de estos castella a los que alude la Crónica de Saint Maixent no eran sino los burūŷy de los que hemos hecho mención, torres y defensas menores yuxtapuestas de forma más o menos cercana a los poblados, como ocurre también en Datos (Badules, Zaragoza) o en El Castillejo (Mainar, Zaragoza), otros dos pequeños asentamientos de época ibérica también reocupados posteriormente por poblados andalusíes (BURILLO MOZOTA, 1980: pp. 87-9 y 95-8; C.A.A. 89-90, 1993b: pp. 121-2; C.A.A. 89-90, 1993c: pp. 21-6). La aparición de estas pequeñas fortificaciones secundarias en la documentación cristiana es desde luego excepcional. Un buen ejemplo puede encontrarse sin embargo en el convenio que en II 80 tuvo lugar entre Alfonso II y Español de Castellote sobre el propio castillo de Castellote, por el cual el monarca donaba, entre otros derechos, "... omnes furtitudines que sunt uel erunt in omnibus terminis dicti castri de Casteloth..." (GAZULLA, 1928: pp. 372, doc. III). El hecho de que estas torres aparezcan mencionadas en la documentación como castella no debe llamar a engaño; es su entrega a tenentes lo que justifica tal nomenclatura, de la misma forma que es su integración en el dominio territorial de otro castellum lo que justifica su mención como furtitudines. Nada hace pensar pues que tales castella pudieran ser considerados verdaderos husșūn en época andalusí, como parece ocurrir a partir del siglo VII/XIII en Levante (BAZZANA et alii, 1988: p. 293) o en Andalucía (QUESADA, 1995: p. 12). No existe pues traducción directa. La desarticulación de la estructura territorial andalusí se expresa así mediante una radical rearticulación terminológica en las fuentes escritas de los vencedores.

\section{Toponimia}

De otros asentamientos nuestros datos son únicamente toponímicos, como ocurre en los casos de Torrecilla del Rebollar (Lám. I I) o Torre los Negros por ejemplo (sobre el tema, UBIETO, 1987). En ninguno de estos dos puntos ha sido posible constatar un registro arqueológico que remita a la etapa andalusí. No obstante, las obras de fortificación en estos lugares conservadas actualmente deben ser seguramente tardías (GUITART, 1987; GUITART, 1988) y, desde luego, resulta difícil caracterizarlas como simples torres o torrecillas. La aparición de estos topónimos en la documentación hacia muy principios del siglo XIII, aunque sólo tiene valor indicativo, permite sin embargo localizar su implantación y, por tanto, la existencia de las estructuras defensivas a que aluden, entre I |42, cuando los aragoneses ocupan definitivamente Daroca, por entonces todavía in extremo sarracenorum, como recoje su segundo fuero (ESTEBAN, 1959: p. 362, doc. 8), y I205, cuando aparecen documentados por vez primera en la zona un buen número de topónimos formados a partir de "Torre-" o "Tor-" (ESTEBAN, 1959: p. 376, doc. II). Aunque no es imposible pensar que las torres de Torrecilla del Rebollar y de Torre los Negros fueran creaciones ex novo, producto de la colonización cristiana de la segunda mitad del XII (GARGALLO, 1996, I: p. 273, n. 252), la importancia económica y estratégica de los puntos en que se asientan, hace pensar más bien en topónimos creados en referencia a fortificaciones heredadas de época andalusí. Algo similar debió ocurrir en el mismo valle del jiloca con pequeñas aldeas como turrem de Carcere, Torrelacárcel, donada por Alfonso I al monasterio de Montearagón junto a Singra en 
I| 28 (LEDESMA, 199|: p. 7I, doc. 47), es decir antes de que la colonización de la zona se haga efectiva con la puebla definitiva de Daroca. Posiblemente el caso sea similar al de Torre Invidia, que aparece citada en I I 82 (DURÁN, I987; ESTEBAN, 1959: p. 128), localizable seguramente en el yacimiento del Cerro del Cortijo/Cerro de la Lomilla (Villafranca del Campo) (SIMÓN et alii, 1991: p. 434). Las características formales de estas torres nos son desconocidas, aunque es posible que algunas de ellas siguieran el modelo del torreón todavía conservado en Villacadima (Monreal del Campo, Teruel), es decir, de planta cuadrada y construidas en tapial (SIMÓN, 1991).

No es sin embargo improbable que algunos de estos topónimos procedieran incluso de época andalusí. Hay que tener en cuenta que ni la propia Qutanda, ni la mayoría de tóponimos cercanos que aparecen citados en las fuentes escritas, como Badra, Qalamūša o L.nqa, son de origen árabe. El mismo topónimo "Alpeñés", un probable primitivo romance "Alpenyoso", si no es un aporte traído por colonos procedentes del Bajo Gállego, es claramente romance, apareciendo constatado en los documentos mozárabes de Toledo en el siglo XII con la forma penyōša (GALMÉS DE FUENTES, 1983: pp. 53 y 66). Lo mismo puede decirse de otros topónimos que parecen perdurar desde la Antigüedad Tardía, caso de Pancrudo, Lechago, Lechón, Anadón, Corbatón, Lidón, Retascón, Cucalón, Bañón u Otón, microtopónimo de Loscos, y otros más complicados como Olalla, un probable hagiotopónimo preárabe "[Santa] Eulalia", arabizado en Ulaliya, frente a Santa Eulalia, topónimo de colonización en el valle del jiloca. Sólo hișn ar-Rayāhịn, el "castillo de los Arrayanes", es topónimo árabe de forma segura y también probablemente Allueva (GIMÉNEZ, 199|). Nada hace pensar por lo tanto en la instalación de importantes grupos tribales bereberes como los que J. A. Sesma y otros $(1996,75)$ han detectado en el vecino iqlimm de Belchite y Almonacid, donde, por otra parte, la lista de topónimos árabes es bastante más amplia (SESMA, 1996: pp. 75 y 8I). En este sentido, es suficientemente conocida la referencia del Fath al-Andalus (siglo VII/XIII), que, al aludir a la revuelta bereber del 741 , dice: "Todos los árabes de los extremos septentrionales de la Península fueron repelidos hacia el Centro, excepto los que habitaban en Zaragoza y en su región, porque eran allí más numerosos que los bereberes los cuales no podían atacarlos" (cit. FIERRO, 1987: p. 19).

\section{CONCLUSIONES}

Es evidente que la escasa extensión territorial y cronológica analizada, el que va desde el final del siglo V/XI hasta la huida masiva de las comunidades campesinas andalusíes del Jiloca y del alto Huerva en el primer cuarto del la siguiente centuria, no permite extraer conclusiones de valor general sobre la organización del poblamiento de los aqālimm de la Marca Superior. Ciertamente el caso de Qutanda y su iqlīm no tiene porqué ser paradigmático. En todo caso, merece la pena destacar una par de aspectos de interés. En primer lugar, la ausencia de cualquier indicio de la existencia de "castillos campesinos", según el modelo propuesto por los investigadores de la Casa de Velázquez (BAZZANA et alii, 1988) y sugerido por J. A. Sesma y otros $(1996,79)$ para el iqlimm de Belchite. Ni los hușūn conocidos permiten sospechar la presencia en ellos de albacares destinados a la defensa colectiva y autónoma de los campesinos, ni las menciones en la documentación aragonesa a castella permiten entrever la existencia de dichos "castillos campesinos". Por el contrario, la organización del espacio campesino controlado por el iqlimm de Cutanda parece mucho más cercana al modelo de la Marca Media, carácterizado por la presencia de torreones que coronan o se yuxtaponen a las alquerías, como ocurre en la zona de Madrid (CABALLERO y MATEO, 1990), Soria (CANALLERO y MATEO, 1988; GAYA, 1932; GAYA, 1944; MARTÍNEZ, 1979; DOMÍNGUEZ, 1984-5), Guadalajara (ALMAGRO GORBEA, 1976) O Albarracín (ALMAGRO BASCH, 1977). La Marca Superior, al menos en su sector medirional, parece seguir también este modelo de defensa rural, con alquerías y burūŷy dotadas de defensas autónomas en forma de torreones, asentamientos dependientes de husụun de carácter plenamente estatal, que actúan como receptores intermediarios de los impuestos generados por aquellas en su tránsito hacia las ciudades de carácter secundario, 
en este caso seguramente Daroca, y de aquí hasta llegar a la metrópoli (umm) zaragozana.

Este modelo no presenta alteraciones significativas desde su creación en torno a mediados del siglo V/XI, cuando aparece ya perfectamente configurado, como pone de manifiesto el grueso de los materiales, especialmente cerámicos, encontrados en las prospecciones, hasta su desaparición en el primer cuarto del siglo VI/XII, cuando la imparable marcha hacia el sur de los aragoneses provoque la huida en masa de las poblaciones campesinas de todo el sector del jiloca. Ello lleva a sopechar que, en última instancia, la sociedad que desmontaron los aragoneses durante ese primer tercio del siglo VI/XII fue la misma que carácterizará a las taifas y cuya expresión territorial ha sido analizada con anterioridad. La escasa incidencia del poder almorávide primero y mardanisí después en la Marca Superior fue clara.

\section{APÉNDICE I. Principales fuentes escri- tas musulmanas de carácter geográfico sobre Cutanda}

I) AL-'UDRT̄: Aḥmad b. 'Umar b. Anas al-'Udِrī (393/I002478/1086), Kitāb tarșî̀ al-ajbār wa-tamwì al-ātār wa-l-bustān fī garāilb al-buldān wa-l-masālik ilà gami' al-mamālik:

Distrito (iqlīm) de Cutanda (Qutanda), a sesenta millas de Zaragoza; en este distrito nace el río Baltas (nahr Balțaš), de un desfiladero que se llama fâŷy Badra.

-AL-AHWĀNĪ, 'A. (ed. parc.) (1965) Ahmmad b. 'Umar b. Anas al-'Uḍri Fragmentos Geográfico-históricos de Al-Masalik ila gami' al-mamalik, p. 23. Madrid.

-GRANJA, F. de la (trad. parc. esp.) (1966) "La Marca Superior en la obra de al-'Udîn'”, Aragón en la Edad Media, 8, p. $459, n^{\circ} 8$.

2) AL-IDRĪST̄: Abū 'Abd Allāh Muḥammad b. Muḥammad b. 'Abd Allāh b. Idrīs al-Hammūdī al-Hașanī al-ma'rūf bi I-šarif al-Idrīsi (493/ I099-560/I I 65), Kitāb nuzhat al-muštaq fījtirāq al-āfāq:

De Valencia a Zaragoza, pasando por Cutanda, nueve jornadas

De Valencia a Cutanda, tres jornadas

De Cutanda a hiș ar-Rayāhinn, castillo fuerte, bien poblado, dos jornadas
-DOZY, R. y DE GOEJE, M. J. (eds. parc. franc. [climas $I^{\circ}$ a $\left.\left.4^{\circ}\right]\right)$ ( I 866) Edrisi, Description de l'Afrique et de l'Espagne, pp. $191-2$ (texto) y p. 233 (traducción). Leiden.

-SAAVEDRA, E. (trad. parc. esp. [clima 5º], en Ubieto, A. (reimpr.) (1974) Idrisi. Geografia de España, p. 30. Valencia.

3) YĀQUT: Abū 'Allāh Yāqūt b. 'Abd Allāh al-Hamāwī al-Bagdādī al-Rūmī (ca. 575/l | 79-626/I229), Mu'ŷam albuldān:

\begin{abstract}
Qutanda:
Es el nombre de un pueblo (balda) en al-Andalus, en la marca (al-tagr) de Zaragoza. En ella tuvo lugar una batalla entre musulmanes y cristianos (ifranŷ) en la que murió como mártir el iman de los tradicionistas de al-Andalus, el cadí Abū 'Ali al-Husayn b. Muḥammad b. Fîrruh b. Hayawa b. Sukkara al-Șadafi al-Ṣaraqustī en el mes de rabi' I del año 5 |4/mayo del I I2I, a los sesenta años de edad
\end{abstract}

\section{Kutanda:}

Es el nombre de un pueblo (balda) en al-Andalus, donde tuvo lugar una conocida batalla entre musulmanes y cristianos (ifranŷ) en el año 5/4/II21 y en la cual murió mártir Abū I-Hasan b. Fîruh al-Șadafî, conocido por Ibn Sukkarra al-Andalusī. El nombre de firuh o firruh es el nombre del hierro en las lenguas bárbaras (barbariya). Había nacido pasado el año $450 / 1058$

-WÜSTENFIELD, F. (ed.) (I 866-72) Jacut's geographisches Wöterbuch, t. IV, p. 37. Leipzig.

-ABD AL-KARIM, G. (trad. parc. esp.) (1974) "La España musulmana en la obra de Yāqūt", Cuadernos de Historia del Islam, 6, pp. 242-3 y 266, respectivamente.

4) AL-MAQQART̄: Abū I-'Abbas Ahmad b. Muḥammad al-Maqqarī (ca. I590-I631), Nafḥ al-țīb min gusn al-Andalus al-rațīb wa-dِirk wazīihā Lisān ad-Dìn Ibn al-Jațīb:

[Cutanda]... es de la zona de Daroca, distrito de Zaragoza, en la frontera superior. Fueron derrotados los musulmanes $y$ fueron muertos cerca de veinte mil de los voluntarios, y no fue muerto nadie del ejercito...

-DOZY, R.; DUGAT, C.; KREHL, L. y WRIGHT, W. (ed. de la | ${ }^{\text {a }}$ mitad) (|855- |86I, reimpr. 1967) Analectes sur l'histoire et la littérature des Arabes d'Espagne. Leiden-Amsterdan, pp. 758-760.

-GAYANGOS, P. (trad. parc. ingl.) (1843, reimpr. 1964) The History of Mohammedan Dynasties in Spain, t. II. Londres-Nueva York, p. 304.

-UBIETO, A. (1981) Historia de Aragón. La formación territorial, p. 162. Zaragoza. 


\section{POST SCRIPTUM}

Ya concluido este trabajo ha visto la luz un interesante artículo de A. Martín Costea (1997): "Sobre el iqlimm musulmán de Cotenda y otros textos medievales", Mas de las Matas, 16, pp. |25-156, donde se defiende la localización del distrito de Cutanda en la cuenca del Guadalope (Teruel). Desgraciadamente, no es posible estar de acuerdo en esta ocasión con las hipótesis del autor. El iqlīm de "Cotenda" jamás existió y desde luego el de Qutanda no es posible localizarlo bajo ninguna circunstancia en torno al Guadalope. El error proviene seguramente de la traducción del $5^{\circ}$ clima del Kitāb nuzhat al-muštaq fījtirāq al-āfāa de al-Idrīsī hecha por Saavedra en 1901 y reimpresa en versión facsimil por A. Ubieto $(1974,40)$. Efectivamente, Saavedra transcribe "Cotenda", pero como J. A. Souto $(1992,128)$ deja claro, aunque en Yāqūt aparece la forma K.t.nda sin vocalizar, la utilizada por al-'Ud̆rī, que es quien hace referencia explicita al iqlimm, es precisamente Qutanda, perfectamente vocalizada, como también ocurre en otro pasaje de Yāqūt. Ello no obsta para que sea razonable pensar en la existencia de un iqlim, en torno al Guadalope, pero, en todo caso, resulta imposible identificarlo con el de Cutanda, y mucho menos con el inexistente iqlim de "Cotenda". Dozy no estaba equivocado.

\section{BIBLIOGRAFÍA}

ABD AL-KARIM, G. (1974): "La España musulmana en la obra de Yāqūt", Cuadernos de Historia del Islam, 6, pp. I354 (monográfico).

ABID MIZAL, J. ( 1989): Al-Idrisi. Los caminos de al-Andalus en el s. XIl. Madrid.

AGUADO VILLALBA, J. (1983): La cerámica hispanomusulamana de Toledo. Marid.

ALMAGRO BASCH, M. (1956): "Calamocha y el Poyo del Campo (Teruel) en relación con el Cid Campeador", Estudios dedicados a Menéndez Pidal, t. Vl, pp. 6I3-639. Madrid.

ALMAGRO BASCH, M. (1977): "Excavaciones en la Peña del Castillejo (Tramacastilla, Albarracín)", Noticiario Arqueológico Hispánico, V, p. 377. Madrid.
ALMAGRO GORBEA, A. (1976): "Las torres bereberes de la Marca Media. Aportaciones a su estudio", Cuadernos de la Alhambra, XII, pp. 279-3I2.

ANDRÉS y VALERO, F. (1960): "Castillos turolenses. Notas históricas acerca de los fronterizos con Castilla", Teruel, 24, pp. 145-175.

ARENILLAS, M. et alii (1996): La presa de Almonacid de la Cuba. Del mundo romano a la llustración en la cuenca del río Aguasvivas. Madrid.

BARCELÓ, M. (1984): "Sobre la divisió administrativa de Mayurqa", en Sobre Mayūrqa, pp. 89-95. Mallorca.

BARCELÓ, M. et alii (1988): Arqueología medieval. En las afueras del "medievalismo". Madrid.

BAZZANA, A. (1982): "Typologie des édifices castraux de l'ancien Sharq al-Andalus', Chateaux-Gaillard, IX-X, pp. 30I-328.

BAZZANA, A.; CRESSIER, P. y GUICHARD, P. (1988): Les chateaux ruraux d'al-Andalus. Histoire et archéologie des hiușūn du sud-est de l'Espagne. Madrid.

BENABOUD, M. y BENSBAA, M. (1993): "Privatisation and inheritance in andalusian documents during the period of Murabitun", Al-Qanțara, XIV/2, pp. 259-274.

BENAVENTE, J.A. y LASA, C. (1995): “Alcañiz en época islámica", en J. A. Benavente (coord.), El castillo de Alcañiz, pp. 23l-267. Teruel.

BOLÒS, J. (ed.) (1993): Paisatge i societat a la plana de Lleida a l'Edad Mitjana. Lérida.

BOSCH VILÀ, J. (1959): Historia de Albarracín y su sierra. Albarracín musulmán. Teruel.

BURILLO JIMÉNEZ, M. (199|a): "Los Villares. Cutanda", Patrimonio Histórico de Aragón. Inventario Arqueológico. Calamocha, pp. 25।-252. Zaragoza.

BURILLO JIMÉNEZ, M. (199|b): "El Castillejo. Lechago", Patrimonio Histórico de Aragón. Inventario Arqueológico. Calamocha, pp. 275-276. Zaragoza.

BURILLO IIMÉNEZ, M. y ZAPATER, M. A. (199|): "El Castillico Cervera. Cutanda", Patrimonio Histórico de Aragón. Inventario Arqueológico. Calamocha, p. 243. Zaragoza.

BURILLO MOZOTA, F. (1979): "Un ejemplo de evolución del hábitat: el yacimiento del Castillejo de Lechago (Teruel)", Boletín Informativo de la Excma. Dip. Prov. de Teruel, 56, pp. 15-27. Teruel.

BURILLO MOZOTA, F. (1980): El Valle Medio del Ebro en época ibérica. Zaragoza.

C.A.A. 89-90 (1993a): "Cerro Almada. Villarreal de Huerva", Patrimonio Histórico de Aragón. Inventario Arqueológico. Daroca, pp. 301-302. Zaragoza.

C.A.A. 89-90 (1993b): "Datos. Badules", Patrimonio Histórico de Aragón. Inventario Arqueológico. Daroca, pp. 121. 2. Zaragoza. 
C.A.A. 89-90 (1993c): "El Castillejo. Mainar", Patrimonio Histórico de Aragón. Inventario Arqueológico. Daroca, pp. 215-216. Zaragoza.

CABALLERO ZOREDA, L. y MATEO SAGASTA, A. (1988): "Atalayas musulmanas en la provincia de Soria", Arevacon, 14, pp. 9-15.

CABALLERO ZOREDA, L. y MATEO SAGASTA, A. (1990): "El grupo de atalayas de la sierra de Madrid", Madrid del siglo IX al XI, pp. 65-77. Madrid.

CARA BARRIONUEVO, L. y RODRÍGUEZ LÓPEZ, J. $M^{a}$. (1992): Castillos y poblamiento medieval en la Alpujarra. El ejemplo de Alhama de Almería. Almería.

CORRAL, J. L. (199|): "Método arqueológico y cantares de gesta", Simposio Internacional El Cid en el valle del Jalón, pp. 33-48. Calatayud.

CORRAL, J. L. y MARTÍNEZ, F. ( 1987): "Geografía e historia en el Poema de Mio Cid : la localización de Alcocer", Revista de Historia Jerónimo Zurita, 55, pp. 43-64.

CRESSIER, P. (|99|): "Agua, fortificaciones y poblamiento en el sureste de la peninsular", Aragón en la Edad Media, IX, pp. 403-427.

CURTO HOMEDES, A.; LORIENTE, A.; LANDIN, Ma. R. M. y ROS, R. (1985): "Els nivells islamics en l'excavació en la Plaça de Ntra. Sra. de la Cinta o de l'Olivera de la ciutata de Tortosa (Tarragona)", I Congreso de Arqueología Medieval Española, t. III, pp. 99-II 2.

DOMÍNGUEZ HERNÁNDEZ, L. P. (1984-5): "Tres torresatalayas de la provincia de Soria: Castellanos, Masegoso y La Pica", Acta Mediævalia, 5-6, pp. 257-278.

DURÁN GUDIOL, A. (1987): El castillo-abadía de Montearagón. (siglos XII-XIII). Huesca.

ERITJA i CIURÓ, X. (1993): "Organització de l'espai del districte andalusí de Lleida (finals del s. XI-primera meitat del s. XIII)", Anàlisi Espacial i Arqueologia Medieval. VII Jornades d'Arqueologia Medieval a Catalunya, pp. 39-44. Barcelona.

ESCÓ SAMPÉRIZ, C. y SÉNAC, Ph. (1988): "Bolea (Huesca): una fortaleza de la Marca Superior de al-Andalus", Bolskan, 4, pp. 147- I73.

ESCÓ SAMPÉRIZ, C:; GIRALT, J. y SÉNAC, Ph. (eds.) (1988): Arqueología Islámica en la Marca Superior de alAndalus. Huesca.

ESTEBAN ABAD, R. (1959): Estudio histórico-político sobre la ciudad y comunidad de Daroca. Teruel.

FIERRO, Ma. I. ( I 987): La heterodoxia en al-Andalus durante el periodo omeya. Madrid.

GALMÉS DE FUENTES, Á. (1983): Dialectología mozárabe. Madrid.

GALLART, ।.; GIRALT, J.; MIRÓ, J. M․ (1985): “Excavaciones en el lado norte de la iglesia de Sant Martí (Lleida). Época andalusí y medieval", I Congreso de Arqueología Medieval Española, t. IV, pp. 313-330.
GARCÍA MARCO, F. J. (1993): Las comunidades mudéjares de Calatayud en el siglo XV. Calatayud.

GARGALLO MOYA, A. J. (1996): El concejo de Teruel en la Edad Media, II 77-I 327. (3 tomos). Teruel.

GARGALLO MOYA, A. y SÁNCHEZ USÓN, Ma. J. (1984): "Cuentas de un viaje en el siglo XIV: de Teruel a Zaragoza y Barcelona en I366", Teruel, 7I, pp. 47-I36.

GAYA NUÑO, J. A. (1932): "La torre árabe de Noviercas (Soria)", Archivo Español de Arte y Arqueología, VIII, pp. 219-223.

GAYA NUÑO, I. A. (1944): "Atalayas cristianas de la frontera", Archivo Español de Arte, 62, pp. 124-130.

GAYANGOS, P. de (I 843): The History of Mohammedan Dynasties in Spain, t. II. Londres.

GAZULLA, F. D. (1928-29): "La Orden del Santo Redentor", Boletín de la Sociedad Castellonense de Cultura, t. IX, pp. 90-212 y 370-375 y t. X, pp. 38-4I y 124-126.

GIMÉNEZ RESANO, G. (|99|): "Toponimia árabe de Aragón", I Curso sobre lengua y literatura en Aragón (Edad Media), pp. 23-47. Zaragoza.

GIRALT J. (|99|): "Fortificacions andalusines a la Marca Superior d'al-Andalus: aproximació a l'estudi de la zona nord del districte de Lleida", La Marche Supériure d'alAndalus et l'Occident chrétien, pp. 67-76. Madrid.

GISBERT, J. A. (1985): "La ciudad de Denia y la producción de cerámicas con decoración estampillada. El alfar de la calle Teulada", Sharq al-Andalus, 2, pp. 16|-174.

GRANIA, F. de la (1967): "La Marca Superior en la obra de al-'Udrì', Estudios de la Edad Media en la Corona de Aragón, VII, pp. 447-545.

GUITART APARICIO, C. (1987): Los castillos turolenses. Teruel.

GUITART APARICIO, C. (1988): Castillos de Aragón, t. III. Zaragoza.

HIDALGO, Ma . J. ( 199 |a): "Arrieros. Torrecilla del Rebollar", Patrimonio Histórico de Aragón. Inventario Arqueológico. Calamocha, pp. 419-420. Zaragoza.

HIDALGO, Ma. J. (199|b): "Alto de la Torre la Quin. Bañón", Patrimonio Histórico de Aragón. Inventario Arqueológico. Calamocha, pp. 125-126. Zaragoza.

IBÁÑEZ GONZÁLEZ, J. (|99|): “Época Medieval”, Patrimonio Histórico de Aragón. Inventario Arqueológico. Calamocha, pp. 91-97. Zaragoza.

LACARRA, J. Ma. (1952): "El rey Lobo de Murcia y el señorío de Albarracín". Estudios dedicados a Menéndez Pidal, pp. 5।5-526.

LALIENA, C. y SÉNAC, Ph. (|99|): Musulmans et Chrétiens dans le Haut Moyen Âge: aux origenes de la Reconquête Aragonsaise.París. 
LEDESMA RUBIO, Ma. L. (|99|): Cartas de población del Reino de Aragón en los siglos medievales. Zaragoza.

LEVİ-PROVENÇAL, E. (1957): España musulmana ( $H^{\mathrm{a}}$. de España de Menéndez Pidal, t. V). Madrid.

MALPICA CUELLO, A. (1996): "Entre la arqueología y la historia. Castillos y poblamiento en Granada. Estudio de una política edilicia a partir de la Alhambra", Tecnología y Sociedad: las grandes obras públicas en la Europa Occidental, pp. 289-326. Pamplona.

MANZANO, E. (|99|): La frontera de al-Andalus en época de los omeyas. Madrid.

MARTÍNEZ TERCERO, E. (1979): "Una introducción a estudio de la arquitectura militar mozárabe: la torre de Noviercas y otras de la frontera noroeste", Celtiberia, 57 pp. 19-38.

MENÉNDEZ PIDAL, R. (1943, 2ª ed.): La España del Cid Buenos Aires.

MOLINA, L. (ed. y trad. esp.) (1983): Dikr bilād al-Andalus (una descripción anónima de al-Andalus). Madrid.

MONÉS, H. (1957): "La división político-administrativa de la España Musulmana", Revista del Instituto Egipcio de Estudios Islámicos en Madrid, V, pp. 79-I36.

ORTEGA ORTEGA, J. M. (1996): "Sabios y ciudades en al-Andalus: algunas notas sobre los 'ulama' de Daroca (siglos VIXI-VI-XII)", El Ruejo, 2, pp. I5-32.

RAMÓN FERNÁNDEZ, N. (1991): "Cerro de la Cesta Torre los Negros", Patrimonio Histórico de Aragón. Inventario Arqueológico. Calamocha, pp. 41 I-412. Zaragoza.

SÁNCHEZ MARTÍNEZ, M. (1975-76): "La cora de Ilbira (Granada y Almería) en los siglos X y Xl, según al-'Udri (1993-1085)", Cuadernos de Historia del Islam, 7, pp. 5-82.

SÉNAC, Ph. (1991): "Poblamiento, habitats rurales y sociedad en la Marca Superior de al-Andalus", Aragón en la Edad Media, IX, pp. 389-40I.

SÉNAC, Ph. (1993): "Le château dans al-Andalus: bilan et perspectives de la recherche française", Mélanges de la Casa de Velázquez, XXIX/I, pp. 17|-195.

SÉNAC, Ph. y ESCÓ, C. (|99|): "Le peuplament musulman dans le district de Huesca (VIlle-Xlle siècles)", La Marche Supériure d'al-Andalus et l'Occident chrétien, pp. 5।-65. Madrid.

SESMA, J. y GARCÍA, Ma. L. (1994): "La ocupación desde el Bronce Antiguo a la Edad media en Las Bardenas Reales de Navarra", Cuadernos de Arqueología de la Universidad de Navarra, 2, pp. 89-218.

SESMA, J. A.; LALIENA, C. y UTRILLA, J. ( 1996): "Regadíos andalusíes en el valle medio del Ebro: el ejemplo del río Aguasvivas", Agricultura y regadío en al-Andalus. II Coloquio de historia y medio fisico, pp. 67-84. Almería.
SIMÓN CAPILLA, Ma. P. (199|): "Villacadima-Torreón. Monreal del Campo", Patrimonio Histórico de Aragón. Inventario Arqueológico. Calamocha, pp. 3|3-3|4. Zaragoza.

SIMÓN CAPILLA, Ma. P.; HERNÁNDEZ, S. y JULIÁN, A. (|99|): "Cerro de la Lomilla-Invidia", Patrimonio Histórico de Aragón. Inventario Arqueológico. Calamocha, p. 434. Zaragoza.

SOPENA, Ma. C. (|99|): "La Pedrera. Barrachina", Patrimonio Histórico de Aragón. Inventario Arqueológico. Calamocha, pp. 135-136. Zaragoza.

SOUTO LASALA, J. A. (|99|): "Contribución al estudio del poblamiento del término de Zaragoza en época omeya", La Marche Supériure d'al-Andalus et l'Occident chrétien, pp. 121-129. Madrid.

SOUTO LASALA, J. A. (1992): "El poblamiento del término de Zaragoza (siglos VIII-X): los datos de las fuentes geográficas e históricas", Anaquel de Estudios Árabes, 3, pp. |13-152.

TURK, A. (1978): El Reino de Zaragoza en el siglo XI de Cristo (V de la Hégira). Madrid.

UBIETO ARTETA, A. (1953): "La reconquista y repoblación de Alcañiz", Teruel, 9, pp. 61-78.

UBIETO ARTETA, A. (1973): Los tenentes en Aragón y Navarra en los siglos XI y XII. Valencia.

UBIETO ARTETA, A. (1974): Idrisi. Geografía de España. Valencia.

UBIETO ARTETA, A. (198I): Historia de Aragón. La formación territorial. Zaragoza.

UBIETO ARTETA, A. (1987): "El topónimo Torre/Torres en Aragón", Homenaje al Profesor Juan Torres Fontes, pp. 1682-| 687. Murcia.

UTRILLA UTRILLA, J. F. (1996): "Aprovechamiento hidráulico, distribución del agua y conflictos sociales en el valle medio del Ebro: el ejemplo del río Aguasvivas (siglos XIIXV)", Tecnología y Sociedad: las grandes obras públicas en la Europa Occidental, pp. 65-I I0. Pamplona.

VALLVÉ, J. ( 1986): La división territorial de la España musulmana. Madrid.

VIGUERA, Ma . J. (coord.) (1994): Los reinos de taifas. AlAndalus en el siglo XI ( $H^{\mathrm{a}}$. de España de Menéndez Pidal, t. VIII/I). Madrid.

VILADÉS CASTILLO, J. Ma . (1987): "Cerámica islámica con decoración estampillada de Zaragzoa", II Congreso de Arqueología Medieval Española, t. III, pp. 22I-230. Madrid.

ZANÓN, J. (1986): "Un itinerario de Córdoba a Zaragoza", al-Qanțara, VII, pp. 3I-52. 


\section{RESUMEN}

Cutanda, escenario de la conocida batalla que en el verano de 5/4/I I 20 enfrentó a las tropas aragonesas con las almorávides, fue también centro de uno de los distritos administrativos en que se dividía la jurisdicción de Zaragoza en época andalusí. Se ensaya en este trabajo un acercamiento a la naturaleza de la división administrativa que las fuentes escritas árabes designan con el término de iqlìm a través de la organización del poblamiento de la cuenca del Pancrudo en los últimos momentos de presencia andalusí, a principios del siglo XII (VI de la Hégira).

PALABRAS CLAVE: Marca Superior, Cutanda, iqlimm, sociedad, territorio, administración, poblamiento, hișnn.

\section{RESUMÉ}

Cutanda, scenaire à l'été de $5 / 4 / 1$ | 20 de la victoire des troupes aragonaises d'Alphonse le Batailleur et du désastre almoravide, il a eté aussi centre d'un district administratif appartenant a Saragosse à l'époque de taifas. On essaye dans ce travail une aproximation a la nature de la division administrative que les sources écrites arabes désignent iqlīm en étudiant l'organization du peuplement de la riviére du Pancrudo dans les derniers moments de l'ocupation andalouse, au debut du Xlle siècle (VI de l'Hègira).

PAROLES CLÉES: Marche Superieure, Cutanda, iqlìm, societé, territoire, administration, peuplement, hiș̣n. 


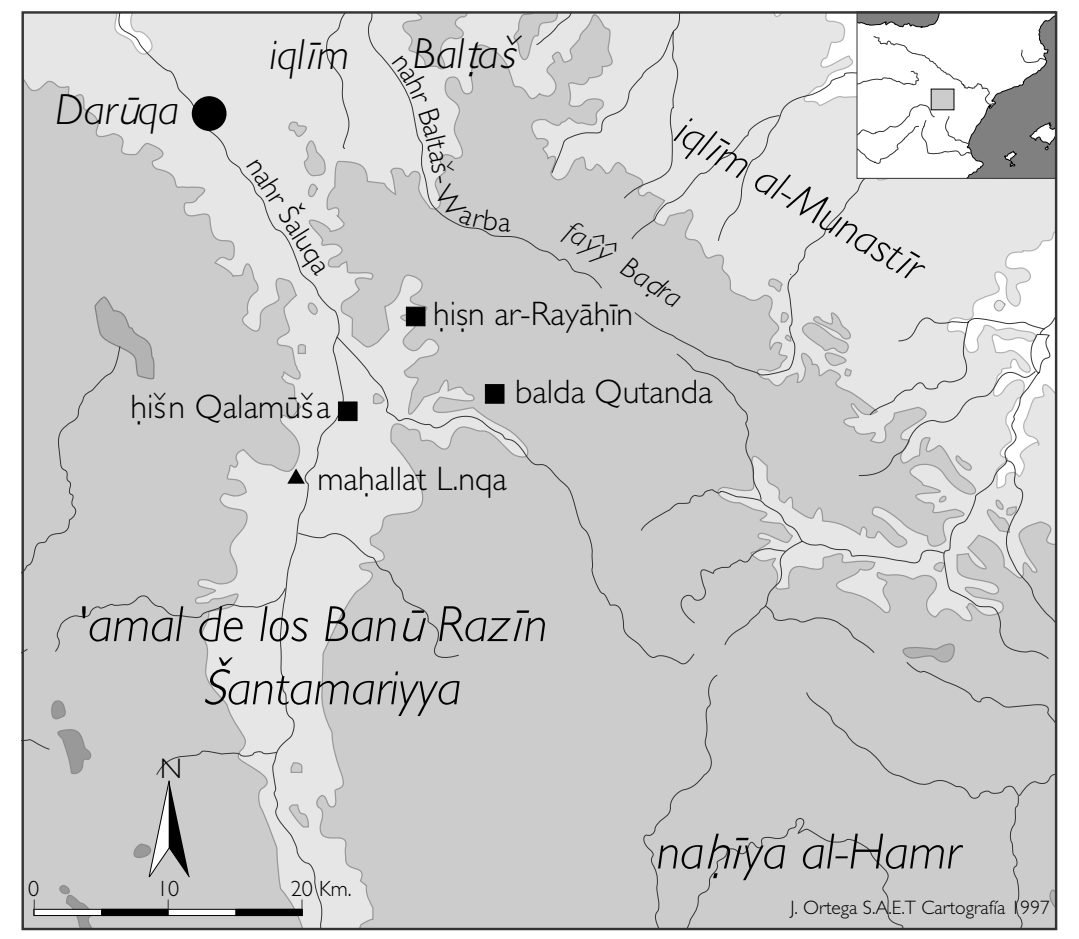

Figura I. El entorno del iqlimm de Cutanda, según las fuentes escritas.

Figura 2. La organización del poblamiento en el iqlimm de Cutanda. Testimonios arqueológicos.

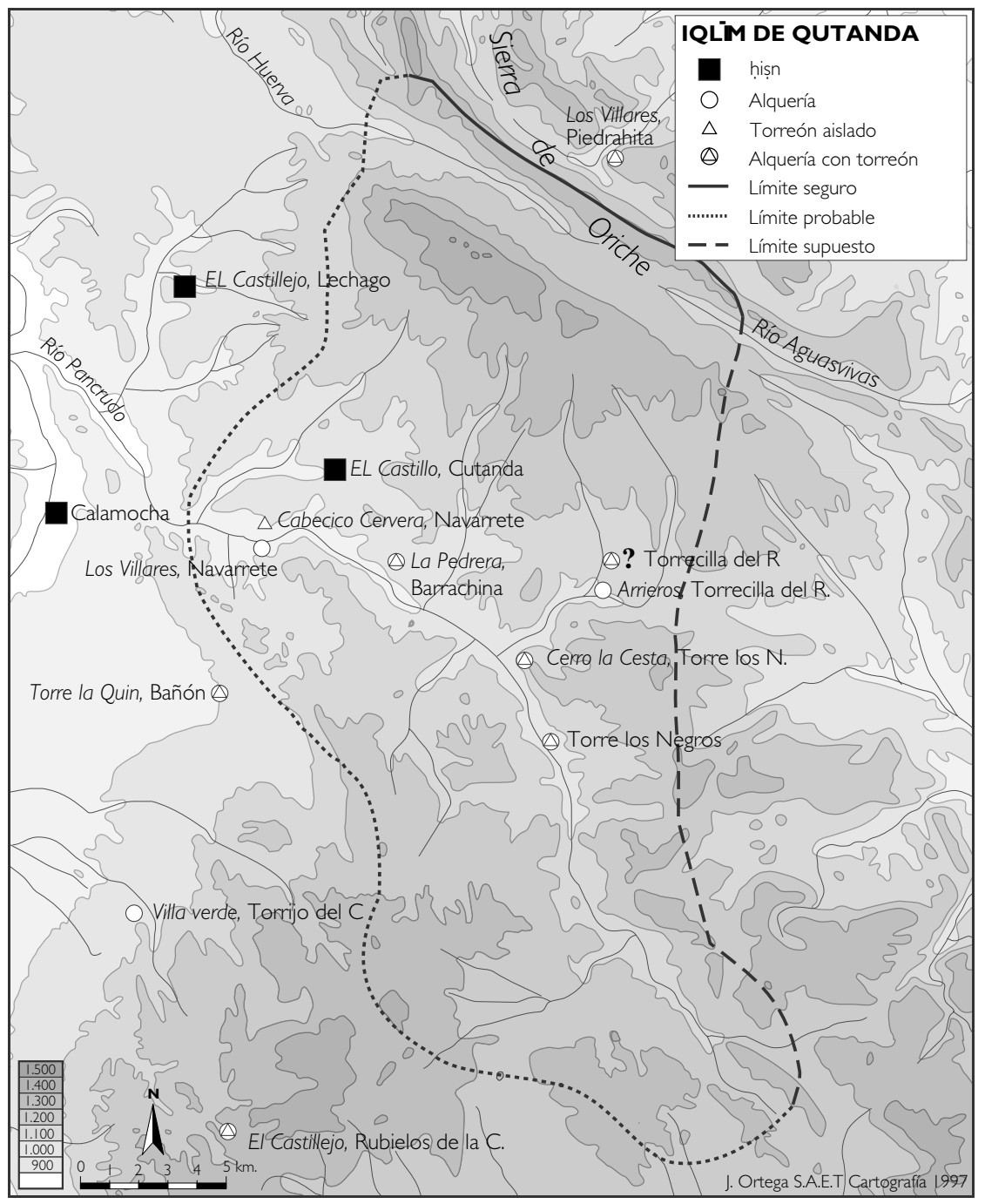




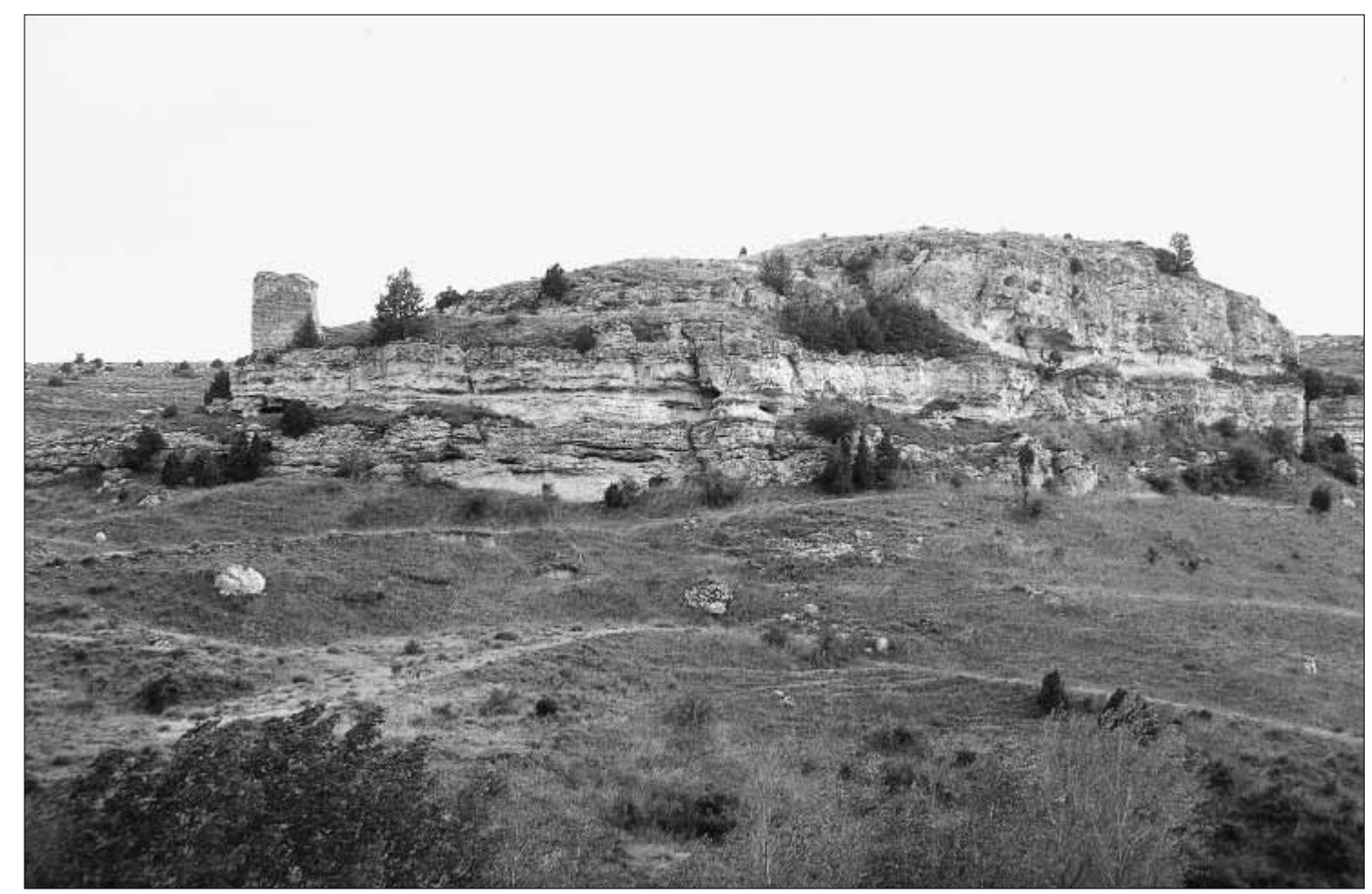

Lám. I. El Castillejo (Lechago, Teruel). Panorámica.

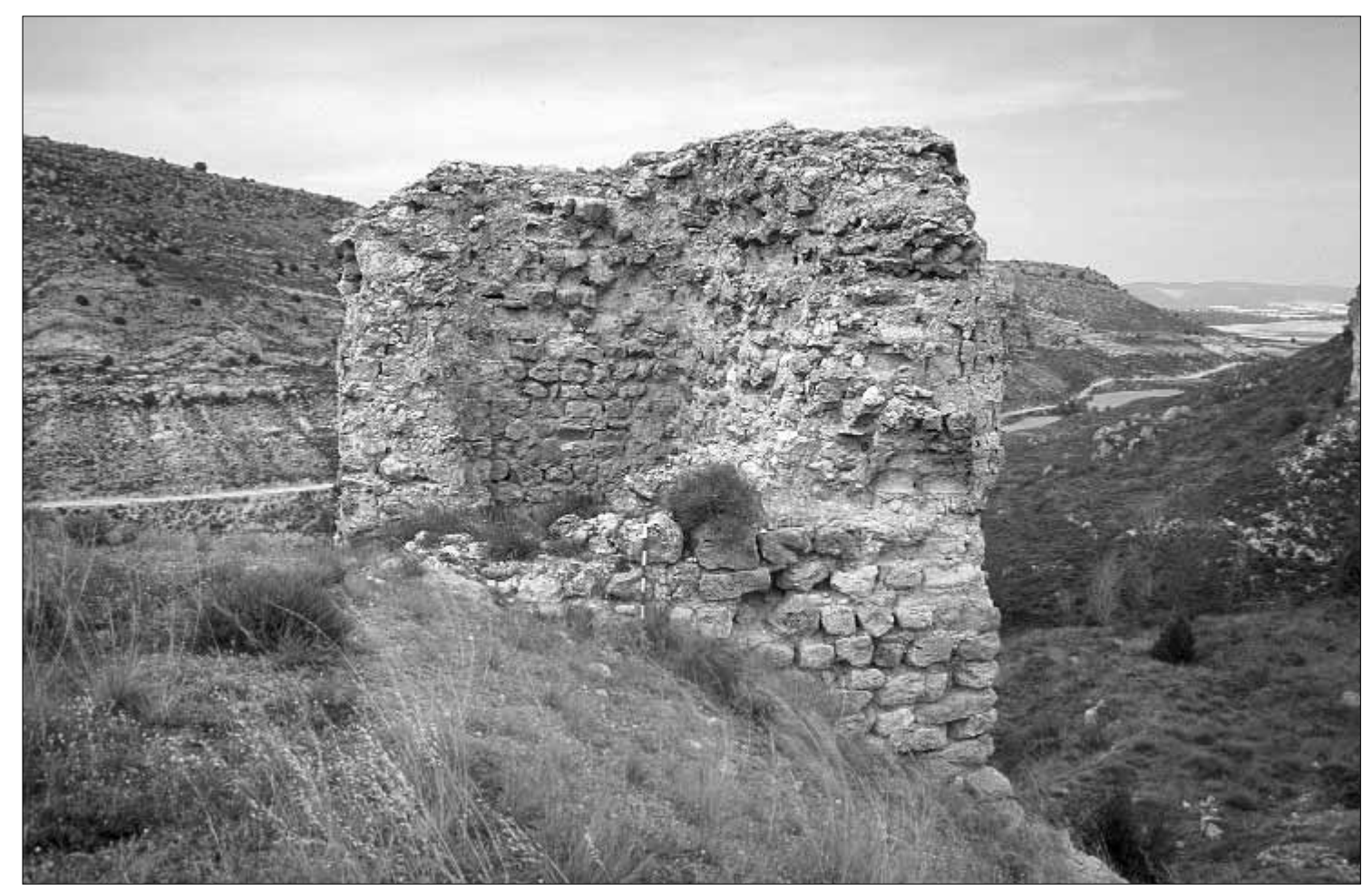

Lám. 2. El Castillejo (Lechago, Teruel). Detalle del torreón. 


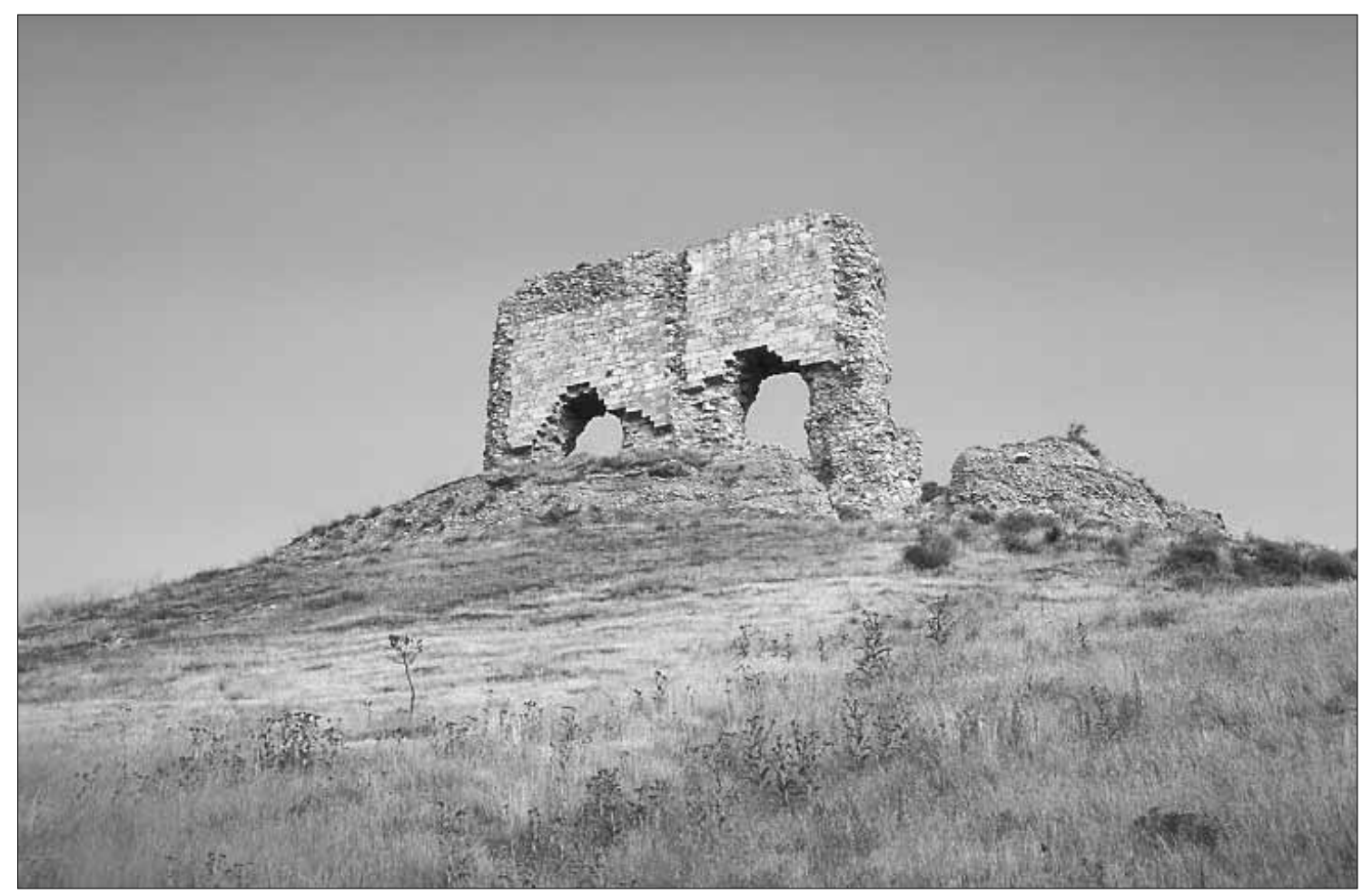

Lám. 3. El Castillo (Cutanda, Teruel). Panorámica.

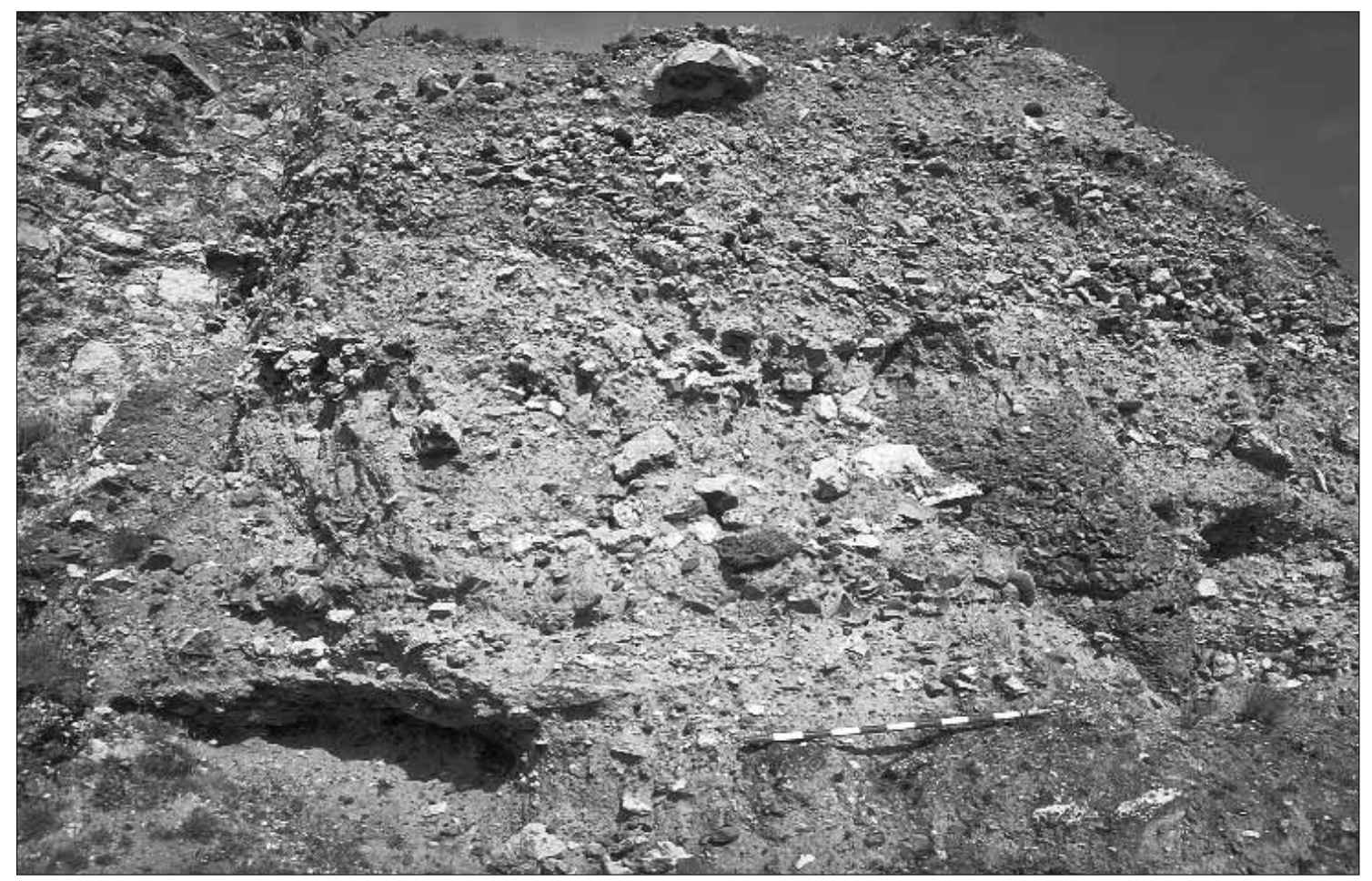

Lám. 4. El Castillo (Cutanda, Teruel). Detalle del nivel de destrucción. 


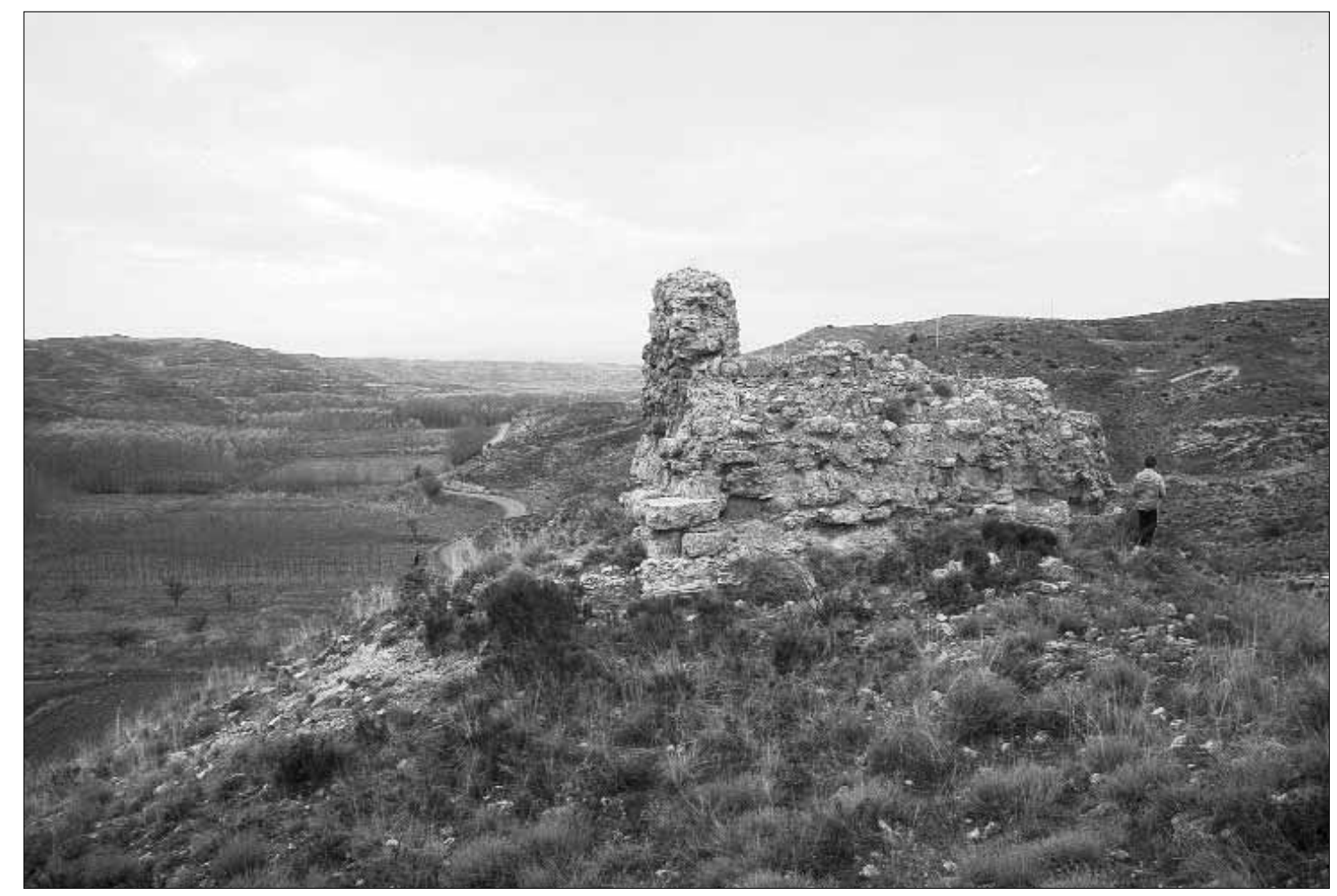

Lám. 5. El Castillico de Cervera (Cutanda, Teruel). Torreón.

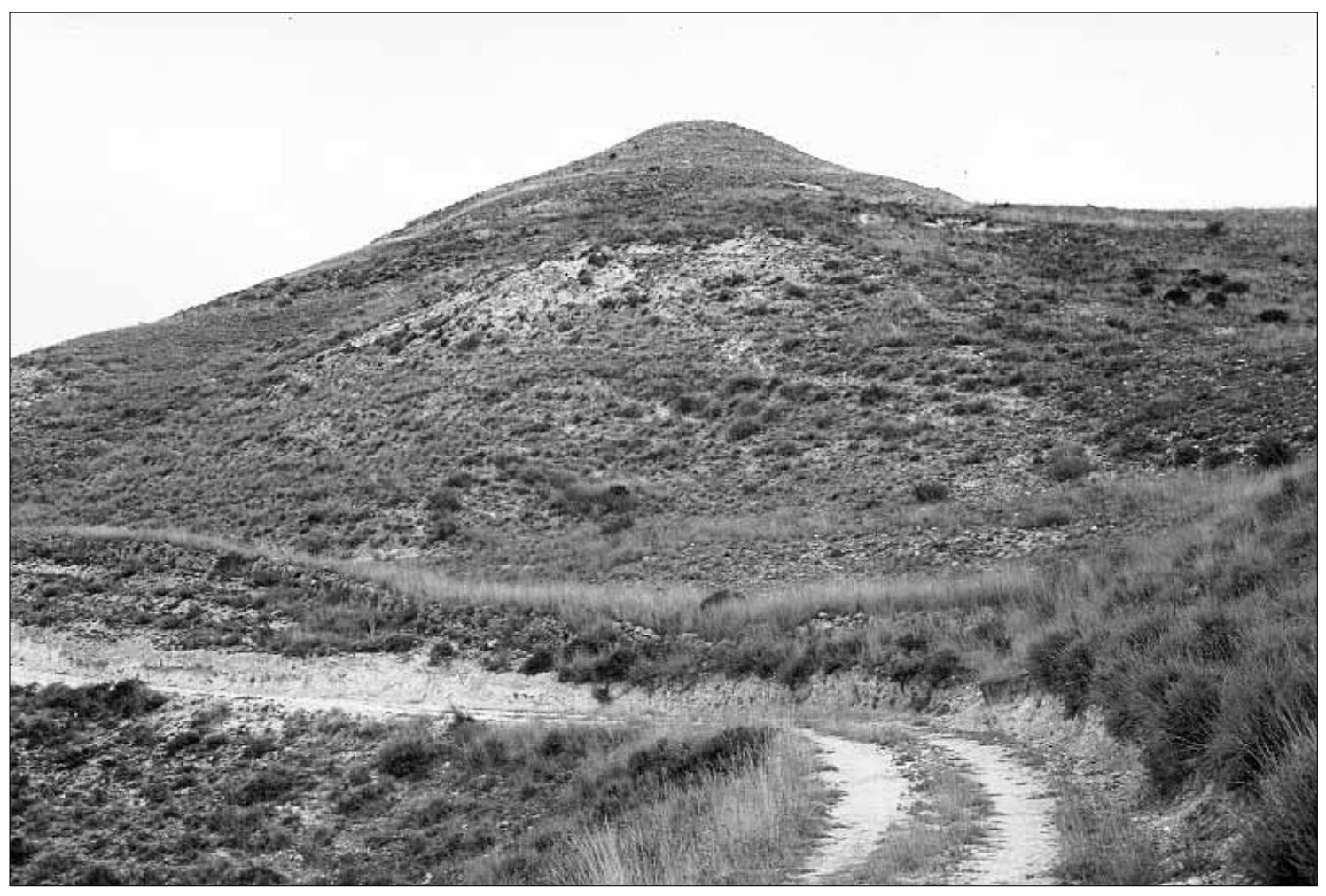

Lám. 6. Cerro de la Cesta /Cabecico Redondo (Torre los Negros, Teruel). Panorámica. 


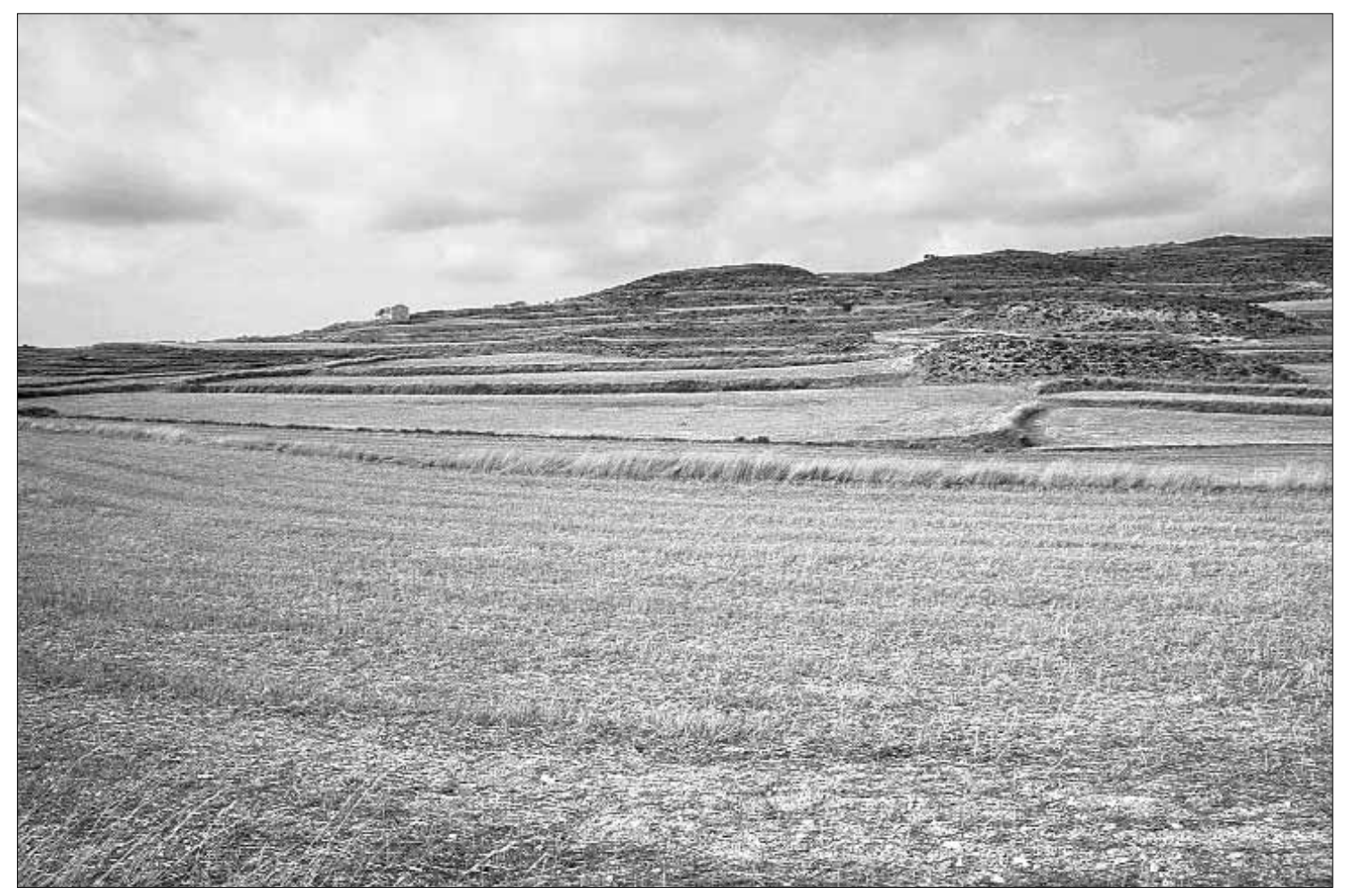

Lám. 7. Alto de la Torre la Quin (Bañón, Teruel). Panorámica.

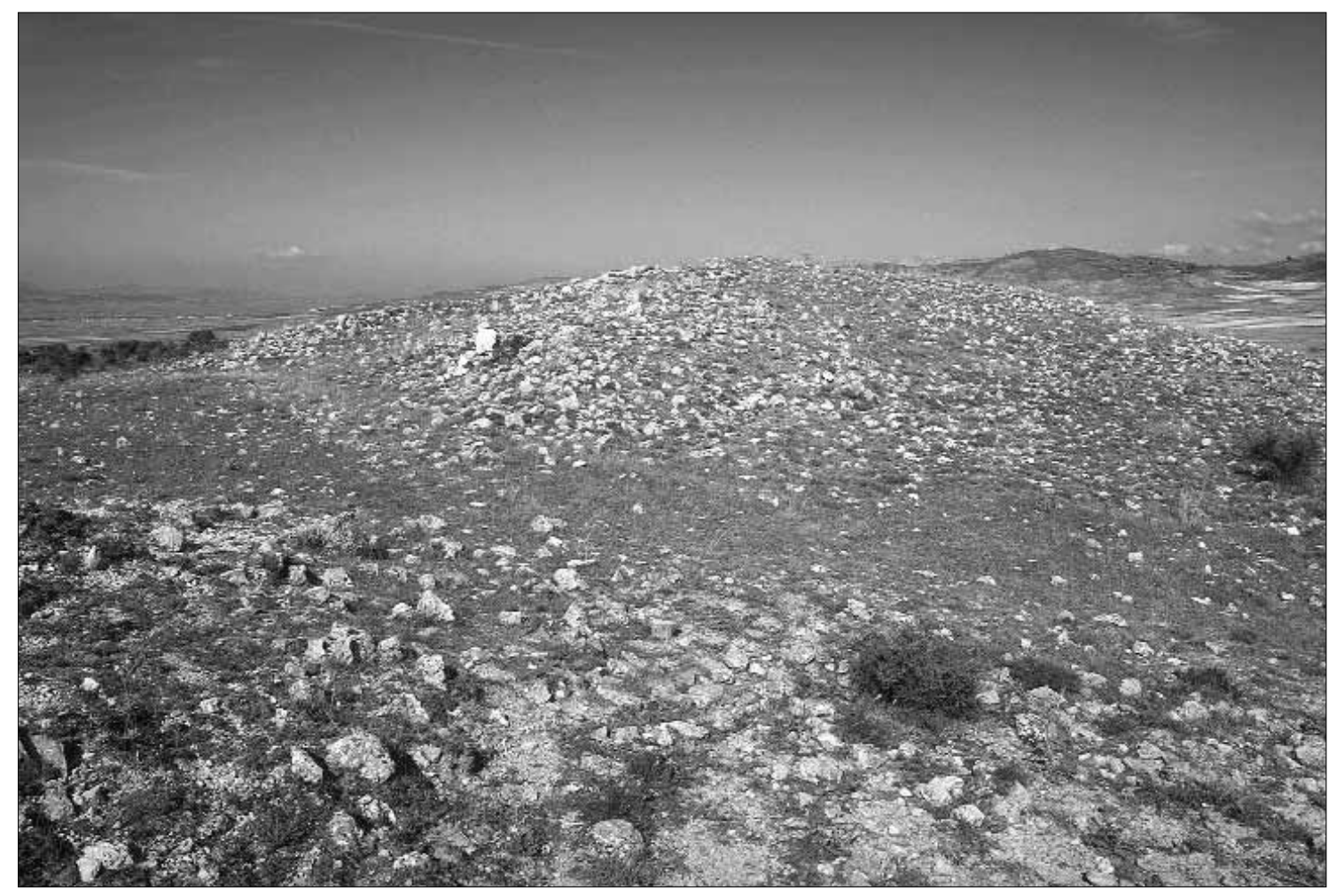

Lám. 8. Alto de la Torre la Quin (Bañón, Teruel). Detalle del torreón. 


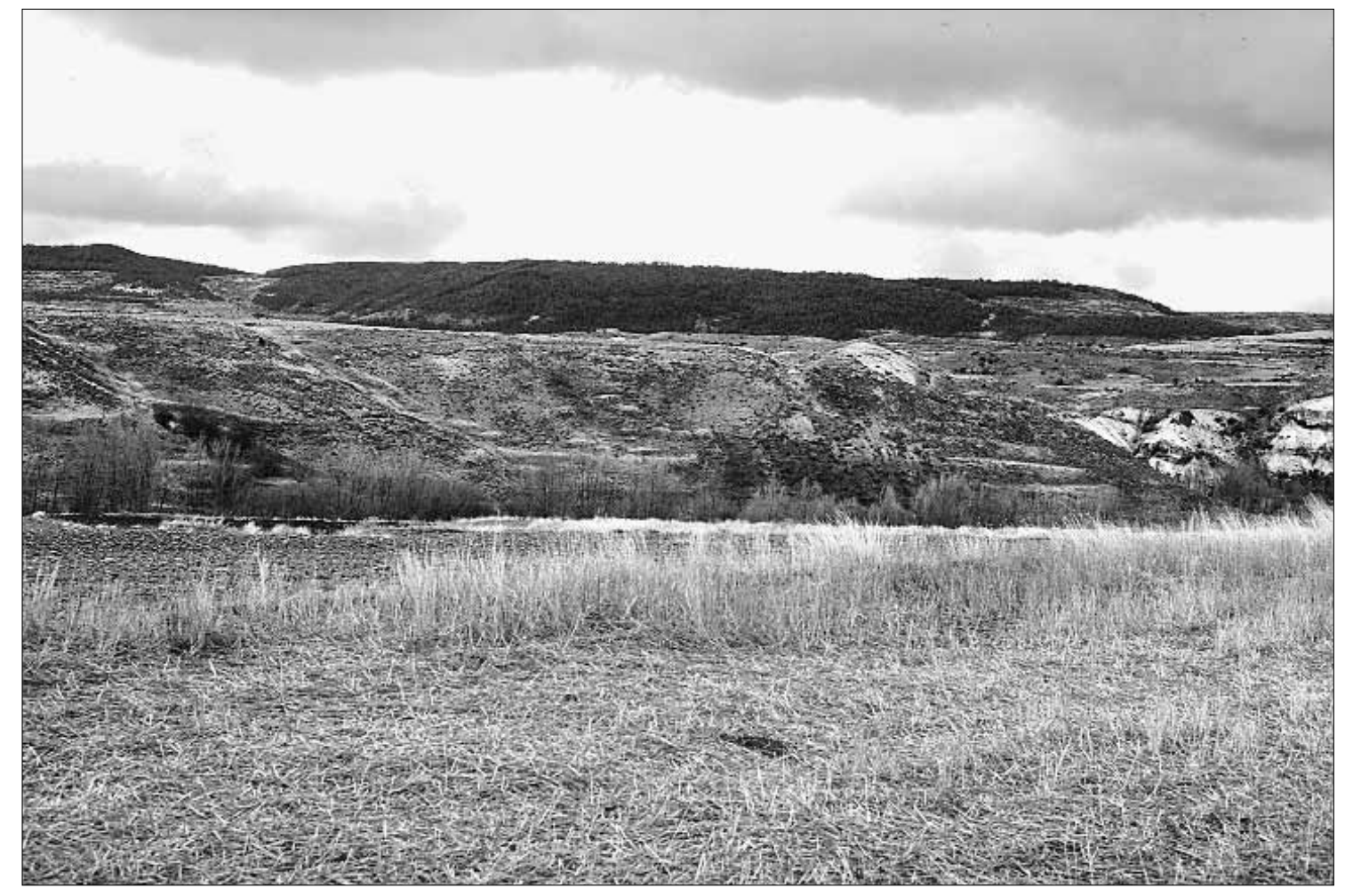

Lám. 9. Arrieros (Torrecilla del Rebollar, Teruel). Panorámica.

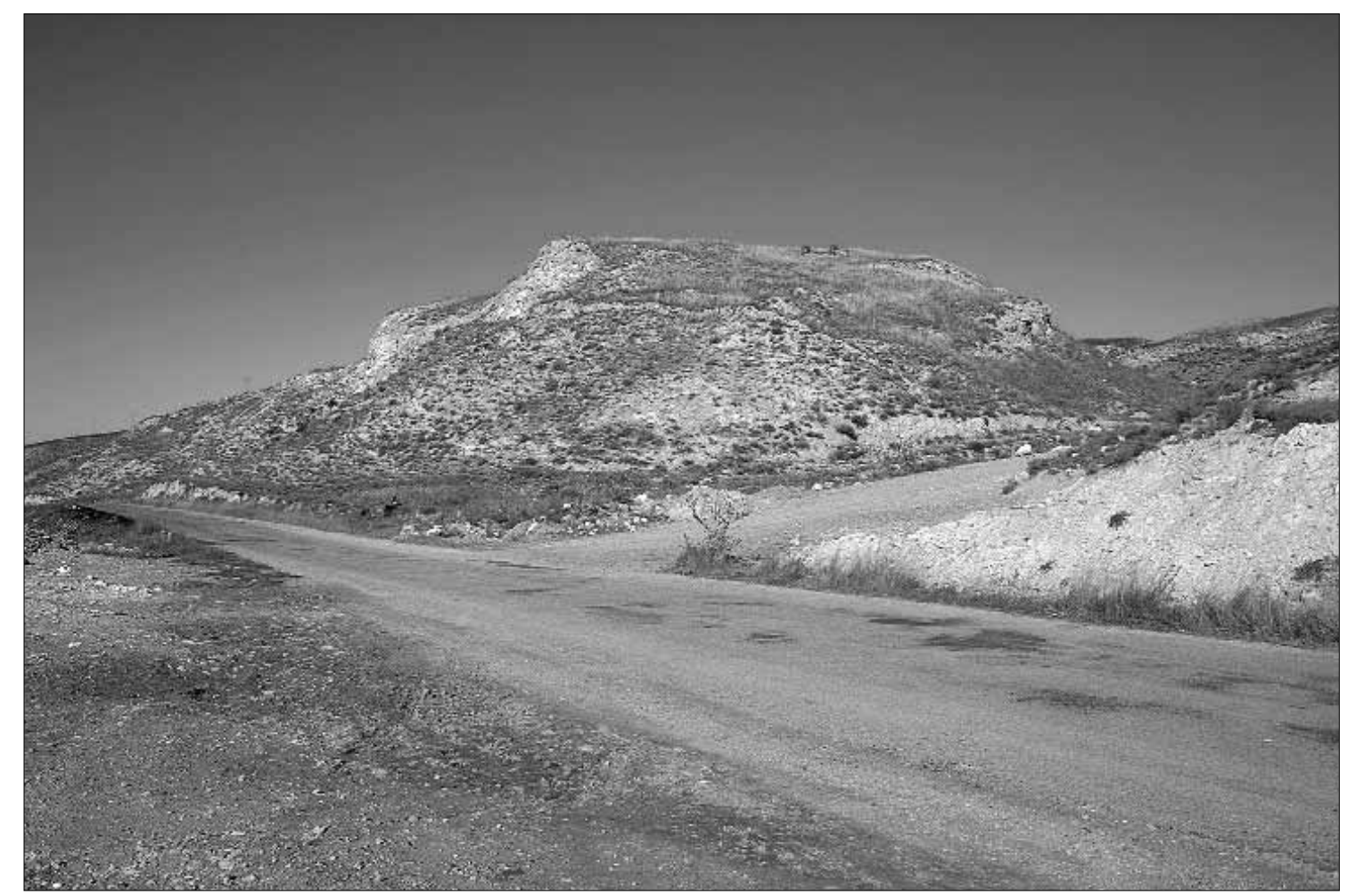

Lám. 10. La Pedrera (Barrachina, Teruel). Panorámica. 


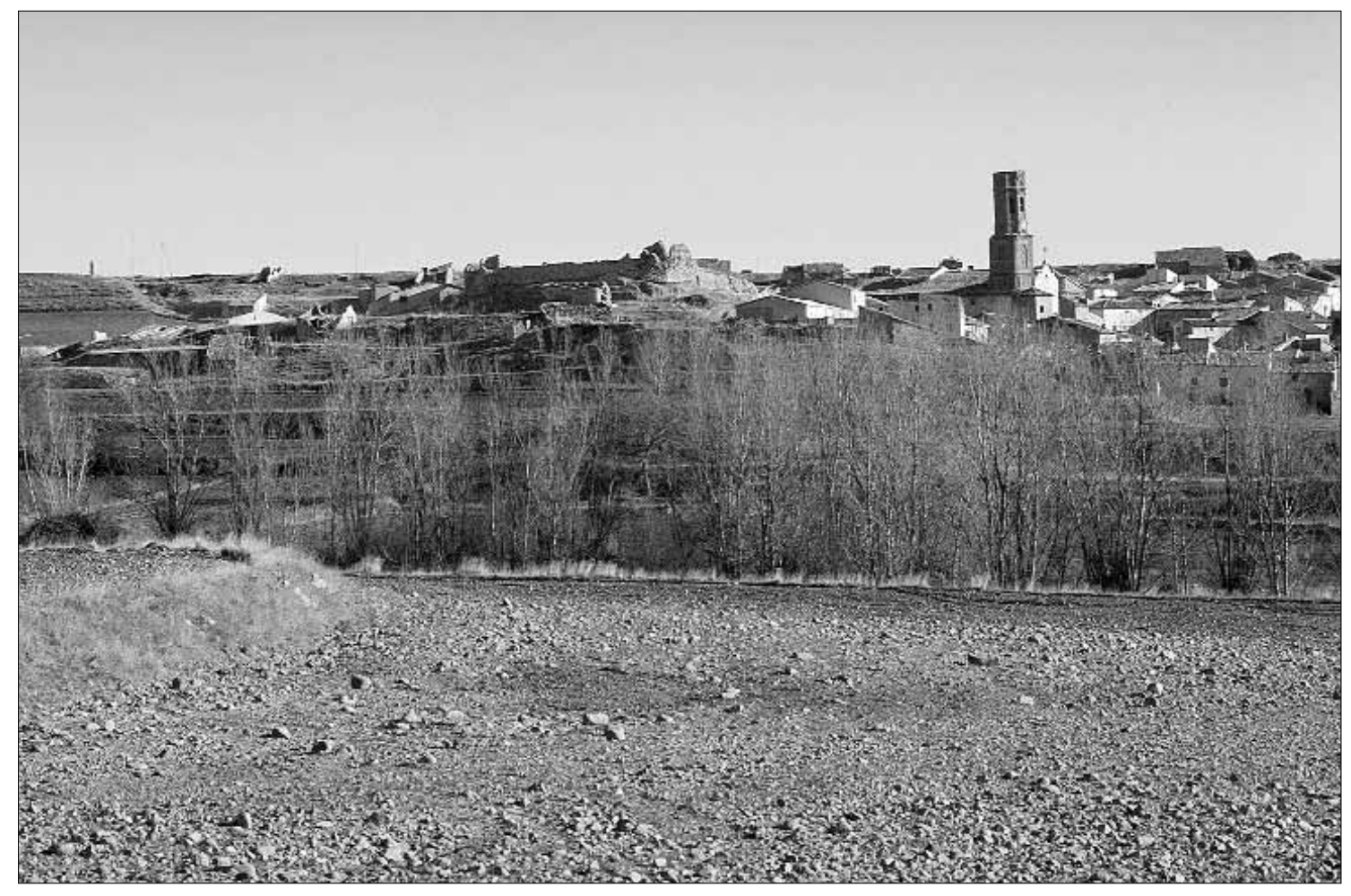

Lám. I I. El Castillo (Torrecilla del Rebollar, Teruel). Panorámica. 